\title{
Clinical guidelines on the management of hepatitis C
}

J C L Booth, J O'Grady, J Neuberger, on behalf of the Royal College of Physicians of London and the British Society of Gastroenterology

\subsection{Guidelines}

1.1 THE NEED FOR GUIDELINES

Hepatitis $\mathrm{C}$ virus (HCV) is a major health care concern in the UK affecting some 200000 to 400000 individuals. The majority of these patients will have chronic HCV infection and many will develop chronic liver disease with the risk of developing cirrhosis and hepatocellular carcinoma (HCC). Successful treatment will arrest the progression of liver disease and so prevent the serious complications of chronic $\mathrm{HCV}$ infection. In addition, treatment will reduce the numbers of $\mathrm{HCV}$ infected individuals.

The relatively high cost of treatment enforces the need for a systematic approach for this condition so that resources are used most effectively. The development of clinical guidelines is important, as these will assist purchasing authorities, providers, clinicians, primary care groups, and patients in making decisions about appropriate treatment.

1.2 THE DEVELOPMENT OF GUIDELINES: RIGOUR OF DEVELOPMENT/SYSTEMATIC CRITICAL REVIEW OF THE LITERATURE

1.2.1 Guideline development group

The development of these clinical guidelines follows a workshop held at the Royal College of Physicians on 3 December 1997. This meeting was jointly coordinated by the NHS Executive, the Royal College of Physicians, the British Society of Gastroenterology, British Liver Trust, and the British Association for the Study of the Liver (BASL). The workshop was attended by hepatologists, gastroenterologists, histopathologists, virologists, general practitioners, clinical nurse specialists, patient representatives, health care economists, and NHS managers. Attendants were chosen to represent key professional disciplines and interest groups likely to be affected by the guidelines. The literature was reviewed by a clinician attending the workshop and the guidelines written under the guidance of a steering committee, which met regularly during the development process. The document was circulated to both clinicians (including gastroenterologists and hepatologists) and non-clinicians for comments before the final guidelines were drawn up (see appendix). The guidelines were presented at the 1999 BASL meeting in London where consensus was achieved on some of the more controversial issues.

Hepatobiliary Unit, Queen Elizabeth Hospital, Birmingham

B15 2TH, UK

J Neuberger

Correspondence to: Dr J C L Booth. prospective and retrospective studies, and in some instances from evidence obtained from expert committee reports or opinions. Where possible a judgement is made on the quality of information used to generate the guidelines. Categories of evidence are classified:

A-RCTs, meta-analyses, or systematic reviews;

B-prospective, retrospective, or cross sectional studies;

$\mathrm{C}$-expert opinion.

The final version of the guidelines represents the views of the steering committee and all areas of disagreement, or where there is a lack of convincing evidence, have been made explicit in the text. It is anticipated that the guidelines will be regularly updated, perhaps on a yearly basis, to allow new developments to be quickly incorporated into the management strategy.

\subsubsection{Context and content}

The guidelines are intended to improve the patient's management from first diagnosis to completion of a course of antiviral therapy and during follow up. Patient preferences must be sought and decisions made jointly by patient and health carer based on the risks and benefits of any therapeutic intervention.

An assessment of the costs of instituting the guidelines must be made. It should be stressed that the costs are "front loaded" and that by preventing disease progression these costs will be offset not only by improved health but also by reducing overall health costs by preventing disease progression.

\subsubsection{Application and presentation}

The national guidelines will be used as a framework for local groups to develop according to local needs.

The resource implications include the high costs for interferon (IFN) and ribavirin treatment and for regular outpatient visits, including diagnostic and monitoring blood tests.

\subsubsection{Statement of intent}

The guidelines should not be regarded as the standard for medical care for all patients.

Abbreviations used in this paper: $\mathrm{HCV}$, hepatitis $\mathrm{C}$ virus; HCC, hepatocellular carcinoma; RCT, randomised control trials; IFN, interferon; CIFN, consensus IFN; NANB, non-A non-B; PCR, polymerase chain reaction; HIV, human

immunodeficiency virus; IVDU, intravenous drug user; HBV, hepatitis B virus; PTH, post transfusion hepatitis; $\mathrm{CAH}$, chronic active hepatitis; $\mathrm{CPH}$, chronic persistent hepatitis; SOD, superoxide dismutase; ELISA, enzyme linked immunosorbent assay; ALT, alanine aminotransferase; LFTs, liver function tests; $\mathrm{MU}$, million units. 
Individual cases must be managed on the basis of all clinical data available for that case and are subject to change as scientific knowledge advances.

\subsection{Background}

2.1 EPIDEMIOLOGY

2.1.1 Prevalence

Since the discovery of $\mathrm{HCV}$ and the development of diagnostic tests, almost all of the non-A non-B (NANB) post transfusion hepatitis $(\mathrm{PTH})$ cases have been shown to be due to $\mathrm{HCV}$ infection. ${ }^{1-7} \mathrm{HCV}$ has been encountered worldwide with WHO estimates of 170 million infected patients worldwide, and up to $90 \%$ of these will progress to chronic liver disease. ${ }^{8}$ In total, 130 countries worldwide have reported $\mathrm{HCV}$ infection.

The prevalence rates of infection in healthy blood donors range from $0.01 \%$ to $0.02 \%$ in the UK and Northern Europe, ${ }^{9} 1 \%$ to $1.5 \%$ in Southern Europe, ${ }^{3}$ to rates of $6.5 \%$ in parts of equatorial Africa. ${ }^{10}$ Prevalence rates as high as $20 \%$ have been found in Egypt. ${ }^{11}{ }^{12}$ Surveillance of HCV in England and Wales has been carried out by the Public Health Laboratory Service Communicable Disease Surveillance Centre since 1990. Estimates suggest that between 200000 and 400000 individuals are infected with the virus in the UK, although the true number remains unknown.

Between 1992 and 1996 a total of 5232 reports of confirmed $\mathrm{HCV}$ infection were received from laboratories in England and Wales (Ramsey 1997). Most were in the 25-34 year age group (38\%) and the 35-44 year age group $(27 \%)$ with more than twice as many reports in males than females. Risk factor information is available for $57 \%$ of cases and the commonest risk factor is injecting drug use $(80 \%)$ followed by receipt of blood products and transfusions $(10.8 \%)$.

During 1996, national surveillance of blood borne infections in UK donors indicated that $0.06 \%$ of new donors were anti-HCV positive. This compares with $0.28 \%$ in France, $0.16 \%$ in Germany, and $0.04 \%$ in Denmark. It is important to realise that blood donors are a self selected group of patients expected to have lower rates of infection than the general population. Transmission of $\mathrm{HCV}$ by blood and blood products in the UK has been virtually eliminated through exclusion of infected donors and by virus inactivation procedures. The risk of an infectious blood donation entering the blood supply is less than 1 in 200000 in England.

\subsubsection{Parenteral transmission}

The main route of $\mathrm{HCV}$ transmission is parenteral, and the majority of patients will give a history of either intravenous drug abuse or a blood/blood product transfusion prior to anti-HCV testing. In 1989, Zuckerman reported the presence of anti-HCV antibody in $85 \%$ of PTH patients, $60-80 \%$ of haemophiliacs receiving blood products, $60-70 \%$ of cases of chronic liver disease with a history of blood transfusion, and $50-70 \%$ of intravenous drug abusers. ${ }^{13}$ Application of second generation diagnostic tests and polymerase chain reaction (PCR) suggest that some of these values are underestimates. ${ }^{14}$ Long term follow up indicates that a large proportion of those patients infected by blood or blood product transfusion will develop chronic viral carriage. ${ }^{15} 16$

Intravenous drug abuse is a major risk factor for $\mathrm{HCV}$ infection with between $50 \%$ and $100 \%$ of intravenous drug users (IVDUs) being anti-HCV positive. Other parenteral routes of transmission include haemodialysis, ${ }^{17} 18$ organ transplantation, ${ }^{19}$ tattooing, and in certain countries traditional practices using non-sterilised knives and indeed the use of non-sterilised needles in large scale immunisation programmes may have contributed to the spread of HCV in these communities. Transmission has also been documented following needlestick injuries (risk estimated $1.8 \%$; CDC 1997) but the frequency of seroconversion following needlestick exposure seems to be low, ${ }^{20}$ and the prevalence of $\mathrm{HCV}$ infection in health workers is no greater than in the general population. ${ }^{21}$

\subsubsection{Non-parenteral transmission}

2.1.3.1 Sexual transmission. Epidemiological studies show low rates of $\mathrm{HCV}$ infection in high promiscuity groups such as prostitutes, homosexuals, and patients with sexually transmitted diseases $^{22-24}$ and suggest a limited role for sexual transmission. A more recent study showed a seropositivity rate of $11.7 \%$ in human immunodeficiency virus (HIV) positive homosexuals who did not have a history of transfusion or IVDU suggesting that sexual transmission occurs and may be facilitated by coinfection with HIV. ${ }^{25}$ Although Alter and colleagues ${ }^{4}$ suggested in 1989 that heterosexual contact was responsible for a proportion of acute NANB cases, more recent studies have failed to support these findings. ${ }^{26}{ }^{27}$ Indeed Hsu and colleagues ${ }^{28}$ were unable to detect $\mathrm{HCV}$ by PCR in semen, urine, stool, or vaginal secretions. The overall rate of anti-HCV positivity appears to be low in sexual partners of HCV infected haemophiliacs ${ }^{29}$ unless there is coexistent HIV infection. In one study intraspousal infection was confirmed by sequence analysis of the $\mathrm{E} 1$ gene $^{30}$ although the risk of transmission in long term monogamous relationships is less that $5 \% .{ }^{31}{ }^{32}$ However, multiple sexual partners, sexually transmitted disease clinic attendance, and prostitution are associated with an increased risk of $\mathrm{HCV}$ infection. $^{33}$

2.1.3.2 Vertical transmission. The risk of vertical transmission seems to be low ( $<6 \%$ of children becoming HCV positive) unless the mother is HIV positive or has a particularly high level viraemia. ${ }^{34-37}$ Breast feeding has not so far been implicated in HCV transmission and the virus has not been found in breast milk. ${ }^{38} 39$

2.1.3.3 Alternative routes of transmission. In families, unapparent parenteral exposure may occur, perhaps by sharing razors or toothbrushes. HCV has been found in saliva ${ }^{39-41}$ and in one study NANB was thought to have been transmitted from chimpanzees by saliva. ${ }^{42}$ Studies of non-sexual household contacts of 
HCV seropositive patients have reported seroprevalence rates varying from $0.5 \%$ to $13 \% .^{43}{ }^{44}$

2.2 NATURAL HISTORY OF HEPATITIS C VIRUS INFECTION

Subclinical HCV infection is the rule with only $10 \%$ of patients reporting an acute illness associated with jaundice. HCV infection rarely causes fulminant hepatitis ${ }^{45}{ }^{46}$ but severe acute $\mathrm{HCV}$ infections have been reported in liver transplant recipients, ${ }^{19}$ patients with underlying chronic liver disease, and in patients coinfected with hepatitis $\mathrm{B}$ virus $(\mathrm{HBV}) .{ }^{47}$ Although the acute illness is usually mild, a high proportion of patients progress to chronic liver disease. ${ }^{8}$ In a study of 135 patients with PTH, 77\% developed chronic disease and of the 65 patients with sequential liver biopsies, $32 \%$ had developed cirrhosis after a mean follow up of 7.5 years. ${ }^{16}$ Only $1 \%$ of these patients had histological remission with the remaining patients having chronic active $(\mathrm{CAH})$ or chronic persistent hepatitis $(\mathrm{CPH})$. However, in the same year Seeff et al published a long term follow up study of patients with post transfusion NANB hepatitis. ${ }^{48}$ A total of 568 patients with PTH and two control groups of 526 and 458 patients who had received transfusions without developing hepatitis were studied. After an average follow up of 18 years, mortality related to liver disease was $3.3 \%$ in PTH cases compared with $1.5 \%$ in the control groups and the majority of deaths occurred in patients with associated alcoholism. It appears therefore that most patients who develop progressive disease do so slowly.

In 1995 Tong et al published a study of 131 PTH cases referred to a centre between 1980 and $1994 .{ }^{49} \mathrm{~A}$ total of 101 patients underwent liver biopsy a mean of 22 years post transfusion. Twenty seven $(20.6 \%)$ had chronic hepatitis, $30(22.9 \%)$ had CAH, $67(51.1 \%)$ had cirrhosis, and seven $(5.3 \%)$ had HCC after mean time intervals from transfusion of 14,18 , 20 , and 28 years, respectively. During the follow up period, 20 (15.3\%) patients died, 19 (95\%) from complications of cirrhosis or the development of HCC. Thus persistent post transfusion $\mathrm{HCV}$ infection does lead to progressive liver disease and in some patients death from related liver failure or the development of HCC although long term follow up studies are required to assess the contribution of $\mathrm{HCV}$ to morbidity and mortality. However, most studies have been conducted at referral centres, reflecting the severe end of the disease spectrum, so that the true numbers of patients with non-progressive or mildly progressive liver disease are unknown.

Viral factors associated with more rapidly progressive disease include high level viraemia, ${ }^{50}$ genotype 1 (especially $1 \mathrm{~b}$ ), ${ }^{51}$ and the degree of viral genetic diversity (quasispecies)..$^{52}$ Route of transmission may be important as patients infected via blood transfusion tend to have more histologically active liver disease. ${ }^{27}$ Other host factors such as immune deficiency, ${ }^{54}$ excess alcohol,,$^{556}$ and coinfection with $\mathrm{HBV}^{47}$ and $\mathrm{HIV}^{57}$ may also influence the rate of disease progression.
There is a variable rate of fibrosis progression with a median time from infection to cirrhosis of approximately 30 years (range 13-42 years). ${ }^{58}$ Independent factors associated with an increased rate of fibrosis progression include age at infection greater than 40 years, daily consumption of $50 \mathrm{~g}$ or more of alcohol, and male sex. There was no association between fibrosis progression and genotype.

In $\mathrm{HCV}$ associated compensated cirrhotics, five year survival is over $90 \%$ and 10 year survival $80 \%{ }^{59}$ A five year follow up showed that the risk of developing HCC was 7\% (1.4\% per year) and $18 \%$ decompensated. After decompensation, prognosis is poor with $50 \%$ survival at five years.

2.3 CLINICAL SPECTRUM OF DISEASE

Infection with the hepatitis $C$ virus results in a variety of hepatic and extrahepatic diseases. In a minority of patients, infection results in an acute hepatitis with symptoms resembling other forms of acute hepatitis. ${ }^{4}$ The mean incubation period is seven weeks and symptoms, if present, last for 2-12 weeks. There are however few reliable studies on the natural history of acute HCV and although the minority of patients clear the virus, the precise numbers are not known.

Patients with chronic $\mathrm{HCV}$ often have no symptoms but may complain of non-specific symptoms such as fatigue, muscle aches, anorexia, right upper quadrant pain, and nausea. Symptoms and signs of chronic liver disease occur later in the disease. However, some patients with chronic HCV cirrhosis remain asymptomatic. Thus the presence of symptoms is a poor marker of the severity of liver disease.

\subsection{EXTRAHEPATIC MANIFESTATIONS}

$\mathrm{HCV}$ infections have been associated with a number of immunological disorders including autoimmune hepatitis, Sjogren's syndrome, lichen planus, thyroiditis, membranous glomerulonephritis, and polyarteritis nodosa. ${ }^{60}$ $\mathrm{HCV}$ is associated with essential mixed cryoglobulinaemia. ${ }^{61-63}$

Recognition of HCV involvement in disorders such as cryoglobulinaemia and idiopathic thrombocytopenic purpura ${ }^{64}$ will allow consideration of IFN therapy for these non-hepatic as well as hepatic diseases.

\subsection{HEPATITIS C VIRUS AND ALCOHOL}

There are high rates of HCV antibody positivity among alcoholic patients. ${ }^{65}{ }^{66}$ Most antibody positive patients are also HCV RNA positive and some studies suggest higher levels of $\mathrm{HCV}$ RNA in this group of patients, ${ }^{67}$ although this remains to be confirmed. The presence of anti$\mathrm{HCV}$ antibodies is associated with more severe liver disease in alcoholic patients.

The importance of alcohol in chronic HCV infection was shown in the recent study of Poynard et al showing that daily consumption of more than $50 \mathrm{~g}$ of alcohol is associated with an increased rate of fibrosis progression. ${ }^{58}$ 
2.6 HEPATITIS C VIRUS AND HEPATOCELLULAR CARCINOMA

$\mathrm{HCV}$ infection is associated with a large proportion of HCCs. In southern Europe and Japan, $50-75 \%$ of HCCs are associated with $\mathrm{HCV}^{65}{ }^{68-70} \mathrm{HCV}$ may cause $\mathrm{HCC}$ as a consequence of cirrhosis or as a result of chronic necroinflammation rather than having any direct carcinogenic effects. Unlike HBV, HCV does not integrate into the host's DNA. The majority, if not all, of patients with HCV associated HCC have established cirrhosis. Both HBV coinfection and excess alcohol seem to have an additional effect on the development of HCC. ${ }^{71} 72$

The natural history of disease progression is slow in HCV related liver disease with estimates of 20-30 years' duration of infection prior to the development of HCC. ${ }^{49}$ In patients with established cirrhosis the rates of development of HCC range between $1 \%$ and $7 \%$ per year. ${ }^{59}$ The role of antiviral therapy in preventing the development of $\mathrm{HCC}$ in $\mathrm{HCV}$ infected cirrhotics is controversial. ${ }^{73}$

\subsection{Diagnosis}

3.1 DIAGNOSTIC SEROLOGICAL ASSAYS

The discovery of HCV in $1989^{74}$ led to the development of an antibody diagnostic assay based on viral recombinant peptides. The first generation tests incorporated a fused antigen of human superoxide dismutase (SOD) and HCV polypeptide (C100-3) used in an enzyme linked immunosorbent assay (ELISA) ${ }^{75}$ The first generation assay lacked sensitivity and specificity prompting the development of second generation assays incorporating antigens from the nucleocapsid (C22) and NS3 (C33) genomic regions. Third generation assays (ELISA-3) have since been introduced incorporating antigens from the putative nucleocapsid, NS3, NS4, and NS5 regions. ELISA-3 tests have a sensitivity of $97 \%$ and have shortened the mean time to seroconversion by $2-3$ weeks. ${ }^{76}$ ELISA- 3 tests are now the most widely used screening tests for $\mathrm{HCV}^{77}{ }^{78}$ but despite the improved specificity, confirmation of positive results is still required as a significant proportion of positive tests will represent false positive results. The false positive rate is especially important in low prevalence settings where the number of false positives may exceed the number of true positives.

A positive ELISA test in a patient with chronic liver disease is probably enough to diagnose $\mathrm{HCV}$ infection and a confirmatory antibody test may not be needed. Confirmatory PCR testing of serum for HCV RNA is suggested for this group of patients.

- Patients with suspected HCV infection should be tested for anti-HCV by an up to date (currently third generation) ELISA test. (Recommendation grade $\mathrm{B}$.)

3.2 CONFIRMATORY ASSAYS

By immobilising HCV antigens on to nitrocellulose strips, recombinant immunoblot assays were developed (for example, Chiron RIBA,
Chiron Diagnostics, Emeryville, California, USA) for confirmation of positive ELISA results. A first recombinant immunoblot assay (RIBA-100) was developed with separately immobilised C100-3, 5-1-1, and SOD antigens.

Second generation RIBA tests were developed with antigens from nucleocapsid (C22) and NS3 (C33) in addition to C100-3 and 5-1-1. Both chimpanzee ${ }^{7980}$ and human studies $^{81-84}$ have suggested that second generation tests allow earlier detection of HCV infection in acute cases and are more frequently positive in chronic cases. A positive second generation RIBA result is associated with $\mathrm{HCV}$ viraemia by PCR in $88-98 \%$ of cases. ${ }^{85-87}$

A positive RIBA test is associated with reactivity with two or more of the antigens, and in the majority $(63 \%)$ of cases $^{88}$ reactivity to all four antigens is detected. An indeterminate result shows reactivity to any one antigen. Several studies have shown that reactivity with c100-3 or 5-1-1 alone is rarely associated with PCR positivity and can be regarded as falsely positive. ${ }^{86-90}$ The majority of patients with lone antibody to c33 and about half of those with antibody to $\mathrm{c} 22$ will be PCR positive and therefore represent true positive results. ${ }^{86} 88899192$

Third generation RIBA tests have been developed incorporating synthetic C22 and C100-3, recombinant C33, and a recombinant NS5 antigen expressed in yeast to replace 5-1-1. This later version has been shown to be positive in most RIBA-2 indeterminate cases $^{9093}$ and to correlate better with HCV viraemia. ${ }^{94}$ However, despite the improved sensitivity of this test, indeterminate results have been observed and HCV RNA is detected in $58 \%$ of these cases. ${ }^{95}$ Thus patients with indeterminate RIBA-3 results must be evaluated for evidence of viral replication and liver disease.

Following a positive antibody test, patients should be referred to the nearest specialist service for further clinical assessment. Specialist clinicians will be responsible for the care of these patients and will ensure some uniformity of approach while facilitating data collection, audit, and research.

\subsection{THE POLYMERASE CHAIN REACTION}

Initial PCR for HCV detection used primers derived from heterogeneous non-structural regions of the virus. The development of primers from the highly conserved 5 ' non-coding region greatly enhanced the detection of $\mathrm{HCV}$ RNA by PCR. ${ }^{96}$ The sensitivity of PCR detection was further enhanced by the development of PCR primers producing shorter PCR products. ${ }^{96}$ The sensitivities of most PCR assays is in the range of 500-1000 equivalents per $\mathrm{ml}$.

Direct detection of the virus using PCR is needed in patients recently infected with the virus and in immunosuppressed individuals who may be antibody negative. In addition, PCR is useful for determining the status of patients with indeterminate antibody profiles and for monitoring antiviral therapies. The sensitivities and specificities of the commercially available PCR tests are very high. Intermittent viraemia is unusual in patients 
untreated with IFN so enhancing the significance of a negative PCR result. ${ }^{97}$

- All patients with positive antibody tests and those patients thought to be at risk of $\mathrm{HCV}$ infection despite negative or indeterminate serological tests should undergo PCR testing of serum. A positive result confirms current viraemia whereas a negative test suggests non-viraemic infection, transient absence of viraemia or recovered infection, a level of viraemia below the detection limit of the assay, or may reflect a non-specific ELISA result. (Recommendation grade B.)

- Patients with positive ELISA but negative PCR should therefore be tested with recombinant immunoblot assay to confirm antibody status. (Recommendation grade $\mathrm{B}$.)

- A qualitative PCR test is recommended in immunodeficient patients with suspected $\mathrm{HCV}$ infection. (Recommendation grade B.)

3.4 LIVER TESTS

The use of routine liver tests to screen for chronic $\mathrm{HCV}$ infection is of limited value as about $50 \%$ of $\mathrm{HCV}$ infected (anti-HCV and PCR positive) patients will have normal transaminase values. Despite normal liver tests these viraemic patients should not be considered "healthy carriers" as the majority will have histological evidence of necroinflammatory liver disease with or without cirrhosis. ${ }^{98}$ Other studies have shown that transaminase levels can be helpful in predicting severity of liver disease, with higher levels associated with more advanced histology, but that they are of limited value in an individual patient. ${ }^{99}$ The value of monitoring transaminases is limited with levels fluctuating from normal to abnormal over time.

- The results of routine liver tests correlate poorly with both necroinflammatory and fibrosis scores found on liver biopsy. (Recommendation grade B.)

3.5 LIVER HISTOLOGY

Liver biopsy is usually performed before initiation of antiviral treatment and remains the most accurate measure of the extent of liver disease. Liver biopsy is usually done in patients with evidence of chronic $\mathrm{HCV}$ infection with abnormal transaminases who are being considered for antiviral therapy. In addition, histological information is useful when other diagnoses such as alcohol induced liver disease are being considered.

The role of liver biopsy in patients with normal transaminases is less clear. Several studies have shown that patients with normal transaminases often have evidence of significant liver disease on liver biopsy. In one study, $11 \%$ of 54 patients with CAH or active cirrhosis had normal alanine aminotransferase (ALT) levels, ${ }^{100}$ and in another more than $50 \%$ of patients with $\mathrm{CAH}, \mathrm{CPH}$, or cirrhosis had normal ALT levels. ${ }^{101}$ Liver biopsy may be considered in HCV positive patients with normal liver function tests (LFTs) and positive for $\mathrm{HCV}$ RNA who are being considered for treatment.

In a further study the use of clinical parameters to predict cirrhosis was found to be inaccurate with a correct diagnosis in less than one third of cases. ${ }^{102}$ In the absence of a less invasive measure of fibrotic liver disease, liver histology remains the gold standard for the assessment of the severity of liver disease.

The biopsy appearance at presentation does not predict the rate of disease progression in an individual non-cirrhotic patient but biopsies taken every $2-3$ years may be useful in predicting outcome if there is progressive accumulation of fibrous tissue.

Some patients will test positive for antibody to HCV, have abnormal LFTs, but will be PCR negative: these patients should be screened for other liver diseases including autoimmune hepatitis and haemochromatosis. Anti-HCV positive patients found to be PCR negative with normal ALT levels should probably be followed up annually until the natural history (virological and biochemical relapse rate) is better known: liver biopsy may be recommended if there is a return of viraemia or a flare up of liver enzymes.

- Liver biopsy is valuable for assessing the status of liver inflammation, potential progression of fibrosis, and the presence or absence of cirrhosis. To clarify these, and to assess suitability for treatment, liver biopsy is recommended for patients found to be viraemic, whether or not liver function tests are abnormal. Standard histological scoring systems by a suitably experienced pathologist should be used to encourage uniformity of histological reports. The risks and benefits of liver biopsies must be fully discussed with the patient. (Recommendation grade B.)

Liver biopsy is probably not indicated after a course of treatment in the majority of patients. A repeat liver biopsy at a remote time interval will provide information on disease progression in both responders and non-responders but the precise timing is not clear.

\subsection{ASSESSMENT OF VIRAEMIA}

Measuring the level of HCV RNA in blood samples has been widely reported with some studies showing varying levels with changes in LFTs $^{103}$ and others suggesting stable levels in individual patients prior to treatment. ${ }^{97}$ However, the role of HCV quantitation in determining disease course remains unclear but the results of recent trials suggest that levels of viraemia are important in tailoring IFN/ ribavirin combination therapy. The level of $\mathrm{HCV}$ viraemia can be measured by quantitative $\mathrm{PCR}^{103-105}$ or by signal amplification techniques such as branched DNA assay. 
3.7 GENOTYPING

Analysis of the conserved 5 'NCR allowed the distinction of three major groups, types 1,2 , and 3. Analysis of samples from around the world led to the discovery of other genotypes. Type $4 \mathrm{HCV}$ was found predominantly in the Middle East and Egypt, ${ }^{106}$ and type 5 sequences were found only in South Africa. ${ }^{107}{ }^{108}$ More recently type 6 has been described from Hong Kong. ${ }^{109}$

Phylogenetic analysis of the NS5 region has allowed the classification of $\mathrm{HCV}$ into six major genetic types and a number of subtypes. So far there has been no overlap in sequence variability between the different classes with nucleotide homologies of $88-100 \%$ between isolates, $74-86 \%$ between subtypes, and 56 $72 \%$ between types.

Typing can be performed in several ways, either serologically with specific peptide ELISAs (serotyping) ${ }^{110}$ or by analysis of PCR products. The latter can be carried out by direct sequencing, ${ }^{111}{ }^{112}$ with type specific primers ${ }^{113}$ on the basis of restriction fragment length polymorphisms ${ }^{114}$ or with sequence specific DNA probes (genotyping). ${ }^{115}$ Genotype helps predict the rate of disease progression ${ }^{116} 117$ and response to antiviral treatment. ${ }^{118} 119$

- Measurement of HCV RNA concentrations in serum and determination of $\mathrm{HCV}$ genotype are recommended and should be used to determine the duration of treatment (see later). (Recommendation grade A.)

\subsection{Treatment}

\subsection{COUNSELLING}

The diagnosis of $\mathrm{HCV}$ causes considerable anxiety to patients and it is therefore essential that all patients receive adequate counselling from a health carer with knowledge and experience in this field. The natural history, treatment options, and likelihood of success should be discussed. Patients should be reassured that $\mathrm{HCV}$ infections are not usually associated with other infections such as HBV or HIV. Although the precise role of sexual transmission remains to be established, ${ }^{2632120121}$ because up to $5 \%$ of spouses of infected patients are infected, ${ }^{30} 31{ }^{122}$ couples in new relationships should be advised to use barrier contraception. In established relationships the small risk of transmission should be explained and the couple should be reassured and left to decide whether to change their sexual practices. The risk of vertical transmission seems to be low ( $<6 \%$ of children becoming HCV positive) unless the mother is HIV positive or has a particularly high level viraemia. ${ }^{34-36}$ Mothers should be advised that breast feeding is probably safe and that so far HCV RNA has not been demonstrated in breast milk. ${ }^{38} 39$

Patients must also be screened for their suitability to receive IFN and ribavirin therapy. The decision to treat must be taken jointly by the physician and patient, based on careful consideration of a number of different factors.
Counselling regarding transmission

- Patients should be counselled on the implications of HCV positivity and advised on the risks of infectivity:

- the natural history is slowly progressive (median time to cirrhosis 28-32 years).

(Recommendation grade A.)

- HCV positive patients should not donate blood, organs, tissues, or semen. (Recommendation grade $\mathrm{C}$.)

-the risk of sexual transmission is small (maximum of $5 \%$ but possibly much less). (Recommendation grade B.) There is insufficient evidence to firmly recommend barrier contraception. (Recommendation grade C.)

-transmission from mother to child is rare (maximum of $6 \%$ ) but transmission rates are higher in HIV positive mothers. (Recommendation grade $\mathrm{B}$.)

-breast feeding is not contraindicated. (Recommendation grade C.)

-household contacts should avoid third party contact with blood by not sharing toothbrushes and razors, and by covering open wounds. (Recommendation grade C.)

-standard precautions for the prevention of transmission to medical personnel and patients is mandatory in health care settings. (Recommendation grade C.)

-needle exchange programmes in drug addicts may help reduce parenterally transmitted infection. (Recommendation grade C.)

Patients should probably not be offered IFN if there is a history of depressive illness, psychosis, untreated autoimmune thyroid disease, neutropenia and/or thrombocytopenia, organ transplantation other than liver, symptomatic heart disease, decompensated cirrhosis, uncontrolled seizures, or evidence of ongoing alcohol or intravenous drug abuse. Patients should have access to reliable refrigeration to store IFN and be able and willing to make regular clinic visits. Adequate warning should be given of the usual initial effects of IFN (fever and malaise) and in particular absence from work may be necessary during the early stages of treatment. Administration prior to sleep with a predose of $0.5-1 \mathrm{~g}$ of paracetamol in the initial weeks of treatment may reduce "flu-like" symptoms associated with initial IFN therapy. Severe side effects from either IFN or ribavirin are infrequent but they may be reversible and dose modulation may successfully reduce the occurrence of side effects while maintaining therapy. Women should be advised not to conceive during a course of IFN.

Ribavirin is contraindicated if there is evidence of end stage renal failure, anaemia, haemoglobinopathy, severe heart disease, uncontrolled hypertension, and for women, where appropriate pregnancy (a pregnancy test prior to treatment is advisable), or no reliable method of contraception. Both men and women should be advised to avoid conception 
during and for six months after IFN/ribavirin combination treatment.

These guidelines apply to adults over 18 years of age; the upper age limit where treatment should be given is unclear but perhaps 65 or 70 years would be reasonable.

The management of patients needs to take into account the differing patient groups according to their transmission routes. These groups include current and ex-injecting drug users, blood or blood product recipients (some identified by HCV lookback), and those with unknown or unapparent transmission (for example, sexual, vertical, household, or occupational). These patient groups may well need different approaches to the way they are managed.

For many current IVDUs there are multiple contraindications to therapy, in addition to concern that continued or recommencing intravenous drug use will result in reinfection with HCV. Some patients may respond to a multidisciplinary approach and antiviral treatment may be considered within the context of detoxification and rehabilitation programmes. Many patients with a history of injecting drugs fail to reattend for follow up after the initial diagnosis of HCV. ${ }^{123}$ Although current IVDUs should not be treated, some patients on oral methadone and particularly those individuals who are committed to rehabilitation programmes may be considered for treatment.

The next large group of patients are those infected with HCV as a result of blood or blood product transfusion. The HCV lookback study has attempted to trace all recipients of $\mathrm{HCV}$ infected blood since the introduction of $\mathrm{HCV}$ antibody screening in September 1991. It has been estimated that up to $60 \%$ of these patients have died due to the original presenting diagnosis, so that the numbers of infected patients presenting for treatment are smaller than originally estimated. One of the most significant issues with those identified by "HCV lookback" is the impact of a new and otherwise unsuspected diagnosis with the risks of significant liver disease. The effects on partners, family, and offspring must be considered. These include issues such as prognosis, infection risk, financial and insurance prospects, and possible medicolegal action. Support and follow up for close contacts of the recipient case are important as they need access to information, counselling, and follow up depending on results of antibody testing.

The group of patients infected by blood products is similar to that infected by blood but may already be affected by the dissemination of HBV or HIV. There is debate about the health impact of $\mathrm{HCV}$ on patients with genetic clotting disorders as well as the need for intervention, including liver biopsy, monitoring, or

- Current IVDUs should not be treated although in selected cases ex-IVDUs taking regular oral methadone may be considered for treatment. (Recommendation grade C.) non-intervention. ${ }^{124}$ The risks and costs of performing liver biopsy may be greater than in other groups of patients and in many of these patients the consequences of the clotting disorder or of coinfection with HBV or HIV are more of a health concern than chronic HCV. The management of patients coinfected with HIV is also controversial, particularly in view of recent developments in antiviral therapy.

An estimated $2-5 \%$ of chronic $\mathrm{HCV}$ infected patients have no behavioural risks but all of the above routes may be the source of possible transmission along with others such as tattooing and poor sterilisation of reused medical instruments.

Significant numbers (up to $40 \%$ ) of patients do not accept treatment or complete the full course of treatment or follow up, ${ }^{123}$ particularly those patients with a history of injecting drugs. Even in those with moderately severe disease, a significant number $(42 \%)$ did not want to undergo treatment.

The role of patient support groups at the local and national level is to be encouraged and perhaps facilitated in the primary care setting. The British Liver Trust organise a national support group network and help in starting up new groups (telephone 01473-276326).

4.2 TREATMENT: GENERAL MEASURES

- Patients should be advised that excess alcohol consumption ( $>50 \mathrm{~g} /$ day) appears to hasten the progression of disease. (Recommendation grade B.)

- Consideration should be given to entering patients with established cirrhosis into surveillance programmes for HCC if their general state of health is sufficiently good that emerging cancers could be appropriately treated. (Recommendation grade C.)

- Patients must be screened for their suitability to receive IFN and ribavirin, with criteria which include proven viraemia and abnormal liver histology. (Recommendation grade C.)

4.3 ANTIVIRAL THERAPY

The treatment of $\mathrm{HCV}$ has evolved from the use of single agent IFN to the use of combination treatment using IFN and ribavirin.

- IFN and ribavirin are currently the only licensed treatments for $\mathrm{HCV}$ in the UK.

- IFN/ribavirin combination is the treatment of choice for IFN naive patients. (Recommendation grade A.)

- IFN/ribavirin combination is also recommended for those patients relapsing after IFN monotherapy. (Recommendation grade A.)

- IFN monotherapy should be considered for those patients in whom ribavirin is contraindicated. (Recommendation grade C.)

- The role of pegylated interferon remains unknown. (Recommendation grade C.) 
4.4 INTERFERON MONOTHERAPY

Numerous studies have now been published to evaluate different IFNs, dosing regimens, and response definitions. The disparate study designs and data analysis make interpretation of the results and comparison with other studies difficult. Few trials have included more than 100 patients per treatment group. ${ }^{125}$

The goal of treatment is the achievement of sustained (24-48 weeks post treatment cessation) transaminase and virological response (PCR negative) with histological improvement. Most of the treatment trials have used similar doses of between 1 and 3 million units (MU) of IFN three times a week for periods of 3-6 months. A dose of $3 \mathrm{MU}$ is more efficacious than $1 \mathrm{MU} \cdot{ }^{126}$ In addition, only those patients receiving $3 \mathrm{MU}$ had significant improvements in liver histology. Alberti et al have shown that $6 \mathrm{MU}$ three times a week leads to a higher proportion of patients with normal ALT at the end of treatment compared with those treated with $3 \mathrm{MU}$ three times a week. ${ }^{127}$ Another study using $10 \mathrm{MU}$ three times a week suggested that sustained response rates could be as high as $50 \%$ although there is a greater risk of treatment failures due to side effects. ${ }^{128}$

Longer treatment regimens of 12 or 18 months also resulted in greater numbers of sustained responders. In one study with a three year follow up period, treatment for 48 weeks led to a sustained biochemical response in $57.1 \%$ of patients compared with $15.4 \%$ in patients treated with the same dose for 24 weeks. ${ }^{129}$ One large trial studied 329 patients treated initially with $3 \mathrm{MU}$ three times a week for six months and then randomised to a further one year of $3 \mathrm{MU}$ or $1 \mathrm{MU}$ three times a week or no further treatment. ${ }^{130}$ A total of 303 patients were randomised and the study end points were normalisation of ALT at the end of treatment during a follow up period of 19-42 months and improvement in histology at the end of treatment. Patients treated with $3 \mathrm{MU}$ for 18 months were more likely to have normal ALT at the end of treatment $(\mathrm{p}=0.008)$, during follow up $(\mathrm{p}=0.02)$, and to have improved histological activity scores at the end of treatment $(\mathrm{p}=0.02)$.

The majority of patients $(>90 \%)$ with sustained response seem to maintain normal ALT with negative HCV-RNA in prolonged follow up (1-6 years). ${ }^{131}$ The histological appearances also improve and in some patients the liver becomes normal.

Poynard at al published a meta-analysis of more than 100 randomised IFN trials ${ }^{125}$ in 1996. The study analysed placebo controlled trials as well as trials using different IFN regimens. Trials were included if they were clearly randomised, using IFN alone, and were using at least one of the following clinical end points: normalisation of ALT during and at the end of treatment (complete ALT response), sustained ALT normalisation (sustained ALT response 6-18 months post treatment cessation), and improvement in histological lesions when biopsy after treatment was compared with biopsy before treatment. Trials were only included if the dose of IFN was at least $3 \mathrm{MU}$ three times per week with a duration longer than six months. All patients were IFN naive.

\subsubsection{Interferon versus placebo}

Using the standard regimen, $3 \mathrm{MU}$ three times per week for six months, sustained response rates were $22 \%$ compared with a natural course of $1 \%$. The response rates were improved when treatment was continued for 12 months, with sustained response in 38\% compared with $2 \%$ in controls. In a smaller number of studies using six months of treatment, histological improvement was demonstrated in $67 \%$ versus $14 \%$ in the control group $(\mathrm{p}<0.001)$. The discrepancy between ALT and histological responses may reflect a natural tendency towards a decrease in histological activity but also may be due to the marked variability in histological end points.

\subsubsection{Dose effect}

In the trials studied for the effects of different doses of IFN, there was no significant difference between 3 or $6 \mathrm{MU}$ given for six months although there was a tendency for greater response rates in the group taking the higher dose. However, there was a significant improvement in response rates at 12 months for the higher dose in terms of complete response $(p=0.005)$ and sustained response $(p<0.001)$ The mean sustained response rate in the $6 \mathrm{MU}$ group was $46 \%$ versus $28 \%$ in the 3 MU group. However, dose reduction due to side effects was more common in patients treated with doses of more than or equal to $5 \mathrm{MU}(22 \%)$ compared with those on $3 \mathrm{MU}(9 \%)(\mathrm{p}=0.01)$. Preliminary data suggest that the dose of interferon should be adjusted to take the patient's weight into account.

- We recommend IFN monotherapy should be initiated at a dose of $3 \mathrm{MU}$ three times per week by injection. (Recommendation grade B.)

4.4.3 Duration effect

In the meta-analysis, longer duration of treatment did not significantly effect the numbers of patients with complete ALT response but did alter the rate of sustained response. At standard doses of $3 \mathrm{MU}$ the mean sustained response rate in the 12-18 month group was $35 \%$ versus $14 \%$ in the six month group $(p<0.001)$. The mean sustained response for the higher dosing regimen ( $6 \mathrm{MU}$ ) was $49 \%$ for $12-18$ months of treatment compared with $29 \%$ in the six month group $(\mathrm{p}<0.001)$.

- IFN monotherapy should be continued for 12 months unless there is evidence of failure to respond (see below). (Recommendation grade B.)

\subsubsection{Type of interferon}

Four forms of alfa-IFN have been evaluated in adequate numbers of $\mathrm{HCV}$ infected patients: alfa-2b, alfa-2a, alfa- $\mathrm{1} 1$, and consensus IFN $(\mathrm{CIFN})$. Both alfa-2b and alfa-2a are produced 
by recombinant DNA techniques using a strain of Escherichia coli genetically engineered to possess plasmid DNA containing an IFN gene from a human leucocyte. Alfa-2b differs from alfa- 2 a by a single amino acid. IFN alfa- $n 1$ is a mixture of nine IFN subtypes produced from a human B lymphoblastoid cell line while CIFN was produced by scanning subtypes of IFN and assigning the most frequently observed amino acid at each position to form a consensus molecule.

At the time of writing there are relatively few studies that have directly compared the different types of alfa-IFN. In one study comparing alfa-2a with alfa-2b, 32 patients were given 6 MU alfa-2a and 68 patients $5 \mathrm{MU}$ alfa-2b, each three times a week for 12 months. The prolonged response rates were similar $(25 \%$ alfa-2a $v 19 \%$ alfa-2b) and side effects were similar, suggesting no major differences between drugs. Comparisons between alfa-2a and lymphoblastoid IFN (alfa-n1) suggest no significant differences in terms of efficacy but there may be more frequent side effects in patients receiving lymphoblastoid IFN. ${ }^{132}$

In one large multinational study involving 1071 patients, the efficacy and safety of lymphoblastoid IFN (alfa-n1; Wellferon) was compared with recombinant alfa- $2 b$ given for 24 weeks in IFN naive patients. ${ }^{133}$ At the end of treatment both biochemical $(36.6 \%)$ and virological responses (IFN alfa-n $137.9 \%$ v IFN alfa-2b $42 \%$ ) were similar. Tolerability and severity of reported side effects were similar in the two groups. During follow up, relapse was more common in patients treated with IFN alfa- $2 \mathrm{~b}$ with a sustained virological response at week 72 of $8.5 \%$ in those treated with IFN alfa-n 1 compared with $4.8 \%$ in those treated with IFN alfa-2b $(p=0.04)$. In the vast majority of patients with a sustained response at one year, liver biopsy specimens showed improvement but there were no differences between the two types of IFN. Thus lymphoblastoid IFN seems to be at least as efficacious as recombinant IFNs and may reduce the post treatment relapse rate.

Further studies have compared CIFN with recombinant IFN (IFN alfa-2b) and have shown similar efficacy and side effect profiles. However, this type of IFN has not been used as often in clinical practice and further studies are needed to determine whether it should be used in place of recombinant or lymphoblastoid IFN. Data from trials using other forms of IFN such as pegylated IFN are expected soon and initial reports suggest encouraging results. At present, there are insufficient data to evaluate the role of pegylated interferon compared with other interferons but once trials are published these guidelines will be re-assessed.

- There is no evidence to suggest that one type of alfa-IFN is superior to another (alfa-2b, alfa-2a, alfa- $\mathrm{1}$, and consensus IFN (CIFN)). (Recommendation grade B.)
4.5 INTERFERON/RIBAVIRIN COMBINATION THERAPY

Ribavirin is a nucleoside analogue that is well absorbed orally and has broad antiviral activity against a variety of DNA and RNA viruses. Ribavirin is administered in doses of 1000$1200 \mathrm{mg} /$ day depending on body weight (above/below $75 \mathrm{~kg}$ ).

\subsubsection{Ribavirin monotherapy}

Initial pilot studies with ribavirin revealed encouraging results with significant biochemical responses during treatment but there was always relapse following treatment withdrawal. There was no effect on HCV viraemia. ${ }^{134} 135$

More recently, randomised, double blind, placebo controlled trials of ribavirin therapy have been reported. Once again there were biochemical responses in most patients treated with ribavirin but no patient became persistently PCR negative. ${ }^{136-138}$

\subsubsection{Combination therapy}

Initial pilot studies revealed encouraging results with the combination of IFN and ribavirin, ${ }^{139}$ particularly in patients who had relapsed after an initial course of alfa-IFN. ${ }^{140}$ Studies in IFN naive patients also showed beneficial effects of combination treatment over IFN alone. Two European studies revealed improved sustained response rates of $47 \%$ and $60 \%$ in the combination groups when compared with IFN alone. ${ }^{141} 142$

The results of a randomised, double blind, placebo controlled trial of IFN alfa-2b with and without ribavirin for chronic hepatitis $\mathrm{C}$ have recently been published. ${ }^{143}$ One hundred IFN naive patients were randomly assigned to treatment with IFN alfa-2b (3 MU three times a week) in combination with ribavirin or placebo for 24 weeks and then followed up for a further 24 weeks. The primary end point was sustained virological response at 24 weeks and one year. Eighteen of 50 patients $(36 \%)$ treated with combination therapy had a sustained virological response compared with 9/50 $(18 \%)$ treated with IFN alone $(p=0.047)$. At the one year follow up, the proportion of patients with a sustained virological response was greater in the combination therapy group $(42 \%$ v $20 \% ; \mathrm{p}=0.03)$. Interestingly, the beneficial effect was most pronounced in patients with high level viraemia.

In the latter half of 1998, two further randomised studies were published on IFN/ ribavirin combination therapy in HCV IFN naive patients (see table 1). In the French study, 832 IFN naive patients were randomised into one of three treatment groups: IFN $3 \mathrm{MU}$ three times a week plus ribavirin 1000-1200 $\mathrm{mg} /$ day for 48 weeks, IFN plus ribavirin in the same doses for 24 weeks, and IFN plus placebo given for 48 weeks. ${ }^{144}$ The primary end point was loss of HCV-RNA at 24 weeks after therapy. The sustained viral clearance rates were $43 \%$ for the 48 week combination therapy, $35 \%$ for the 24 week combination therapy, and $19 \%$ for the 48 week IFN monotherapy. Although the difference between 48 
Table 1 Sustained virological responses (SR;PCR negative 24 weeks after treatment cessation) in naive patients taken from the two multicentre randomised controlled trials published in $1998^{144} 145$

\begin{tabular}{|c|c|c|c|c|}
\hline \multirow[b]{3}{*}{ Study } & \multicolumn{4}{|l|}{$S R$} \\
\hline & \multicolumn{2}{|l|}{ IFN/placebo } & \multicolumn{2}{|l|}{ IFN/ribavirin } \\
\hline & 24 weeks & 48 weeks & 24 weeks & 48 weeks \\
\hline Poynard $^{144}(\mathrm{n}=832)$ & - & $53 / 278(19 \%)$ & $96 / 277(35 \%)$ & $118 / 277(43 \%)$ \\
\hline McHutchinson $^{145}(n=681)$ & $13 / 231(6 \%)$ & $29 / 225(13 \%)$ & $70 / 228(31 \%)$ & $87 / 228(38 \%)$ \\
\hline Total $(n=1513)$ & $13 / 231(6 \%)$ & $82 / 503(16 \%)$ & $166 / 505(33 \%)$ & $205 / 505(41 \%)$ \\
\hline
\end{tabular}

Table 2 Sustained responses (SR; PCR negative 24 weeks after treatment cessation) according to genotype in naive patients taken from the two multicentre randomised controlled trials published in $1998^{144} 145$

\begin{tabular}{|c|c|c|c|c|}
\hline \multirow[b]{3}{*}{ Study } & \multicolumn{4}{|l|}{$S R$} \\
\hline & \multicolumn{2}{|l|}{ IFN/placebo } & \multicolumn{2}{|l|}{ IFN/ribavirin } \\
\hline & 24 weeks & 48 weeks & 24 weeks & 48 weeks \\
\hline \multicolumn{5}{|l|}{ Poynard $^{145}$} \\
\hline Genotype 1 & - & $20 / 179(11 \%)$ & $32 / 177(18 \%)$ & $56 / 180(31 \%)$ \\
\hline Genotype non-1 & - & 33/99 (33\%) & $64 / 100(64 \%)$ & 62/97 (64\%) \\
\hline \multicolumn{5}{|l|}{ McHutchinson $^{145}$} \\
\hline Genotype 1 & $3 / 167(2 \%)$ & $11 / 162(7 \%)$ & $26 / 164(16 \%)$ & $46 / 166(28 \%)$ \\
\hline Genotype non-1 & $10 / 64(16 \%)$ & $18 / 63(29 \%)$ & $44 / 64(69 \%)$ & 41/61 (66\%) \\
\hline \multicolumn{5}{|l|}{ Total } \\
\hline Genotype 1 & $3 / 167(2 \%)$ & $33 / 341(10 \%)$ & $58 / 341(17 \%)$ & $102 / 346(29 \%)$ \\
\hline Genotype non-1 & $10 / 64(16 \%)$ & $51 / 162(31 \%)$ & $110 / 164(67 \%)$ & $103 / 158(65 \%)$ \\
\hline
\end{tabular}

Table 3 Sustained responses (SR; PCR negative 24 weeks after treatment cessation) according to baseline viraemia (expressed as copies per $\mathrm{ml}$ ) in naive patients taken from the two multicentre randomised controlled trials published in $1998^{144} 145$

\begin{tabular}{|c|c|c|c|c|}
\hline \multirow[b]{3}{*}{ Study } & \multicolumn{4}{|l|}{$S R$} \\
\hline & \multicolumn{2}{|l|}{ IFN/placebo } & \multicolumn{2}{|l|}{ IFN/ribavirin } \\
\hline & 24 weeks & 48 weeks & 24 weeks & 48 weeks \\
\hline \multicolumn{5}{|l|}{ Poynard $^{144}$} \\
\hline$>2 \times 10^{6}$ copies $/ \mathrm{ml}$ & - & $24 / 183(13 \%)$ & $48 / 169(28 \%)$ & $64 / 162(40 \%)$ \\
\hline$<2 \times 10^{6}$ copies $/ \mathrm{ml}$ & - & $29 / 95(31 \%)$ & $48 / 108(44 \%)$ & $54 / 115(47 \%)$ \\
\hline \multicolumn{5}{|l|}{ McHutchinson $^{145}$} \\
\hline$>2 \times 10^{6}$ copies $/ \mathrm{ml}$ & $6 / 157(4 \%)$ & $11 / 162(7 \%)$ & $44 / 166(27 \%)$ & $54 / 152(36 \%)$ \\
\hline$<2 \times 10^{6}$ copies $/ \mathrm{ml}$ & $7 / 74(9 \%)$ & $18 / 63(29 \%)$ & $26 / 62(42 \%)$ & $33 / 76(43 \%)$ \\
\hline \multicolumn{5}{|l|}{ Total } \\
\hline$>2 \times 10^{6}$ copies $/ \mathrm{ml}$ & $6 / 157(4 \%)$ & $35 / 345(10 \%)$ & $92 / 335(27 \%)$ & $118 / 314(38 \%)$ \\
\hline$<2 \times 10^{6}$ copies $/ \mathrm{ml}$ & $7 / 74(9 \%)$ & $47 / 158(30 \%)$ & $74 / 170(44 \%)$ & $87 / 191(46 \%)$ \\
\hline
\end{tabular}

Table 4 Sustained response (SR; PCR negative 24 weeks after treatment cessation) rates for cirrhotic patients (includes patients with bridging fibrosis) compared with patients with minimal fibrosis taken from the study of McHutchinson et al ${ }^{145}$

\begin{tabular}{|c|c|c|c|c|}
\hline & \multicolumn{4}{|l|}{$S R$} \\
\hline & \multicolumn{2}{|l|}{ IFN/placebo } & \multicolumn{2}{|l|}{ IFN/ribavirin } \\
\hline & 24 weeks & 48 weeks & 24 weeks & 48 weeks \\
\hline Cirrhosis/bridging fibrosis & $3 / 65(5 \%)$ & $9 / 71(13 \%)$ & $17 / 59(29 \%)$ & $21 / 55(38 \%)$ \\
\hline Minimal/no fibrosis & $7 / 154(5 \%)$ & $18 / 136(13 \%)$ & $51 / 159(32 \%)$ & $62 / 159(39 \%)$ \\
\hline
\end{tabular}

and 24 week monotherapy did not reach statistical significance $(p=0.055)$, differences between both combination regimens versus monotherapy were highly significant $(\mathrm{p}<0.001)$.

In the American Hepatitis Interventional Therapy Group Study, 912 IFN naive patients were randomly assigned to combination therapy for 24 or 48 weeks or IFN monotherapy for 24 or 48 weeks. ${ }^{145}$ The primary end points were virological response (defined as sustained response) and histological improvement at 24 weeks after therapy was discontinued. The virological response rates were $31 \%$ and $38 \%$ for the combination groups ( 24 and
48 weeks therapy) and $6 \%$ and $13 \%$ for IFN monotherapy $(p<0.001$ for comparisons of monotherapy with both combination regimens). Improvements in histology were seen in $57 \%$ and $61 \%$ of cases treated with combination therapy versus $44 \%$ and $41 \%$ for the monotherapy groups. Of the 165 patients who had a sustained virological response, 142 $(86 \%)$ had a decrease in hepatic inflammation regardless of the treatment regimen. Inflammation was also seen in 39\% who had persistent viraemia at follow up.

The results of these randomised studies suggest that combination therapy leads to a sustained virological response in approximately $30-40 \%$ of IFN naive patients (a $2-3$-fold better response when compared with IFN monotherapy (see tables 1-3). Although greater numbers of patients do not complete the course of treatment due to unwanted side effects, the improved response rates suggest that combination therapy is the treatment of choice for $\mathrm{HCV}$ infection. Sustained responses of $29 \%$ for 24 weeks and $38 \%$ for 48 weeks were achieved in cirrhotic patients (see table $4)$.

- Recent results of large randomised controlled studies have shown improved response rates for IFN/ribavirin combination therapy in IFN naive and relapsers compared with IFN monotherapy. (Recommendation grade A.)

- Combination therapy consists of IFN at standard doses (usually $3 \mathrm{MU}$ three times per week) with ribavirin $1000 \mathrm{mg} /$ day for patients weighing $75 \mathrm{~kg}$ or less and 1200 $\mathrm{mg}$ for those weighing more than $75 \mathrm{~kg}$. (Recommendation grade A.)

4.6 WHO TO TREAT-ACCORDING TO BIOPSY The decision of whether to treat is complex. As the treatment is relatively expensive and may not cure most cases, patients need to be selected as those most likely to respond to treatment and also those in whom the impact of treatment is greatest, in terms of halting disease progression and preventing complications. Decisions about treatment should be made after liver biopsy has been performed and patients classified into mild, moderate, or severe disease categories according to histological appearances. Histological appearances are classified as mild if the fibrosis score (stage) is less than or equal to $2 / 6$, and if the necroinflammatory score (grade) is less than or equal to $3 / 18$. If the fibrosis score is $3-5 / 6$ and/or the necroinflammatory score is greater than $3 / 18$, the appearances are described as moderate. If the fibrosis score is $6 / 6$, the biopsy is cirrhotic irrespective of necroinflammatory score.

All liver biopsies should be examined by a histopathologist with experience in liver pathology and who can apply the recently reformed grading and staging scores. ${ }^{146}$ Some pathologists prefer to base the assessment of severity of hepatitis on individual components 
of the grading system. In this case mild hepatitis can be defined as having scores for interface hepatitis and for lobular hepatitis of 0 or 1 out of 4. Confluent necrosis should be absent (score 0 ). Any grade of portal inflammation is acceptable.

In patients with mild slowly progressive disease, it may be best to withhold treatment until more efficacious treatments are available. Others would regard this as the best time to treat, perhaps resulting in higher numbers of responders, and others would argue that the virus rather than the disease process needs to be treated and so all infected patients need to be considered for treatment.

\subsubsection{Mild disease}

Patients with mild disease at presentation represent up to $25 \%$ of patients attending for consideration of treatment. These patients are potentially infectious, and despite minimal disease on liver biopsy, may suffer long term consequences of chronic liver disease. Alternatively, treating these generally clinically well patients with expensive drugs with potentially serious side effects may well be inappropriate unless there is clear evidence of disease progression over time.

Many of these patients have normal serum transaminases although liver biopsy examination reveals some degree of histological abnormality. A recent review of 11 studies revealed that $29 \%$ of such patients had mild or non-specific changes, most $(54 \%)$ had mild changes, but $19 \%$ had chronic hepatitis with moderate degrees of necroinflammatory activity. ${ }^{147}$ These mild disease patients probably will have progressive disease but progression is slow and the patient's life expectancy may therefore not be affected by HCV infection.

Several small studies have tended to show similar response rates with IFN monotherapy to trials of patients with abnormal ALTs and more severe histological changes ${ }^{148}$ but other studies suggest that treatment in this group of patients is ineffective. ${ }^{147}$

At present it is probably appropriate not to treat patients with mild disease on liver biopsy but these patients should be reviewed every six months with repeat liver biopsy every $2-3$ years or if there is a significant change in LFTs (that is, 2-3 times normal levels). If the biopsy reveals worsening necroinflammatory disease and/or fibrosis, treatment should then be considered. In some cases of mild hepatitis, treatment may be instigated at this early stage because of concern about infectivity. The results of trials assessing the response to IFN/ribavirin combination are awaited.

\subsubsection{Moderate disease}

This group of patients are the most important group as successful treatment is likely to have the greatest impact by hopefully preventing progression to cirrhosis and its complications. Therefore, all patients with moderate or severe inflammatory activity with or without fibrosis and any patient with fibrosis not amounting to cirrhosis on liver biopsy should be offered treatment.

\subsubsection{Cirrhotics}

HCV cirrhotics are an important group of patients and studies have shown that liver complications are responsible for $70 \%$ of the mortality of HCV cirrhotics. ${ }^{59}$

4.6.3.1 Compensated cirrhosis. Initial studies suggested a poorer response to IFN monotherapy in cirrhotic compared with noncirrhotic patients. ${ }^{149}$ A recent review of 26 published trials that separated cirrhotic patients from non-cirrhotics revealed a reduced rate of ALT normalisation during therapy $(27 \%$ compared with $53 \%){ }^{150}$ In a smaller group of patients the rate of viral clearance was also reduced (5-10\% compared with 20$35 \%)$. The poor response is more often due to failure to respond rather than to relapse following an initial response. Sustained response rates of $29 \%$ (24 weeks) and 36\% (48 weeks) have been achieved with IFN/ribavirin combination treatment suggesting that treatment may well be justified in this subgroup of patients with notoriously poor response to IFN monotherapy. ${ }^{145}$ Other studies have assessed the effects of IFN on clinical events in cirrhotics. In one study only $16 \%$ of treated patients were rendered PCR negative on treatment; in the follow up period of up to seven years HCC was detected in $4 \%$ of treated compared with $38 \%$ of control patients $(p=0.002) .{ }^{73}$ In two other studies the tendency to develop HCC was reduced in patients treated with IFN, with a particularly strong effect in those few patients with sustained biochemical and virological responses. ${ }^{151}{ }^{152}$ However, these results need to be confirmed in larger studies using IFN/ribavirin combination with longer follow up periods.

4.6.3.2 Decompensated cirrhosis. The probability of survival after decompensation is about $50 \%$ at five years. ${ }^{59}$ There are few data on the use of antiviral therapy in decompensated $\mathrm{HCV}$ cirrhotics.

- In viraemic patients, the decision to offer treatment should be influenced by the histological findings. (Recommendation grade $\mathrm{B}$ ):

-treatment can be reasonably withheld in patients with mild disease (see text) but they should be followed to see if there is evidence of progressive liver disease by the use of repeated biopsy after an interval. (Recommendation grade C.)

-treatment should be offered to those patients shown to have moderate disease (Recommendation grade C.)

cirrhotic patients respond less well to IFN monotherapy but sustained responses have improved with IFN/ribavirin combination treatment. There is no conclusive evidence that treatment in this group of patients delays progression of liver disease or the development of HCC. (Recommendation grade B.)

4.7 PREDICTORS OF RESPONSE

Several factors have been implicated but their accuracy in predicting a response in 
individual patients has been poor. However, some physicians exclude patients from treatment if they have one or more of the pretreatment markers associated with a reduced likelihood of response in an attempt to improve response rates and efficiency of antiviral treatment.

\subsubsection{Pretreatment factors}

Both host and viral factors have been identified by either univariate or multivariate analyses. One initial study suggested a more favourable outcome in young females and in patients with lower pretreatment ALT levels. ${ }^{126}$ Other studies have failed to link female sex to better response but have confirmed that younger patients tend to respond more favourably ${ }^{127}$ and that pretreatment ALT and $\gamma$-glutamyltransferase levels tend to be lower in responders. ${ }^{153}$ The better response in younger patients may reflect a shorter duration of infection in association with less severe histological lesions. Indeed, several studies have shown that absence of cirrhosis and low fibrotic histological scores are associated with better treatment outcomes. ${ }^{119} 127$ One study reported the biochemical response rates in patients treated with IFN for 12 months according to the presence or absence of cirrhosis. Within a six month follow up period, $5.3 \%$ of cirrhotics compared with $40.5 \%$ of non-cirrhotics showed sustained normal ALT levels. ${ }^{149}$ Other studies have shown that the hepatic iron content of non-responders $(1156 \pm 283 \mu \mathrm{g} / \mathrm{g}$ dry weight) tends to be higher compared with responders $(638 \pm 118 \mu \mathrm{g} / \mathrm{g}$ dry weight; $\mathrm{p}<0.05)$. $^{154}$

Viral factors thought to be important in determining treatment response include viral genotype, level of viraemia, and level of viral heterogeneity. Improved responses are found in those patients infected with HCV $2^{118} 155$ or HCV 2 and 3 compared with patients infected with genotype $1 .{ }^{117}$ In a review of 15 IFN trials, sustained response was seen in $18.1 \%$ of HCV 1 infected patients compared with $54.9 \%$ of patients infected with other genotypes. ${ }^{156}$ However, the positive predictive value and accuracy of genotype in predicting sustained response was shown to be fairly poor ( $55 \%$ for predictive value, $72 \%$ for accuracy).

The Benelux study reported on 350 patients randomly assigned to standard IFN monotherapy (3 MU three times a week for 24 weeks) or titrated treatment (6 MU three times a week for eight weeks followed by dose reduction based on ALT levels). A total of 319 patients were evaluable for at least six months of follow up and overall the sustained response rate was no better than $14 \%$. The titrated regimen was no better than standard therapy but in multivariate analysis by logistic regression, infection with HCV 2 or 3 were independent predictors of sustained biochemical response. ${ }^{157}$

Pretreatment levels of viraemia have been studied in relation to response to IFN monotherapy. One study using a competitive PCR quantitation method revealed that sustained responders had significantly lower HCV RNA levels compared with non-responders. ${ }^{158}$ Other researchers have used the branched DNA assay (Chiron Corporation) to measure HCV viraemia. Lau et al found that patients with sustained response to IFN had mean viraemia levels of $0.35 \times 10^{6}$ genomes $/ \mathrm{ml}$, partial responders with relapse had mean viraemia levels of $1.6 \times 10^{6}$ genomes $/ \mathrm{ml}$, and non-responders had a mean viraemia level of $3.1 \times 10^{6}$ genomes/ $\mathrm{ml} .{ }^{159}$ However, recent doubts have been expressed as to the reliability of the bDNA assay, as the sensitivity seems to vary according to genotype.

In the meta-analysis, ${ }^{125}$ the predictive value of low HCV RNA level for a sustained response was $51 \%$, with an accuracy of $68 \%$. Thus level of viraemia may be an important pretreatment variable but better and more reliable methods and studies are needed before this can be used in the decision making process.

Sequence analysis of the E2/NS1 region of HCV by analysing multiple clones from different patients has shown that the degree of variability in this region correlates with response to IFN. ${ }^{160}{ }^{161}$ Responders show little or no sequence diversity in this region compared with non-responders who seem to be infected with a large heterogeneous pool of HCV variants. Viral heterogeneity may reflect higher replication rate, longer duration of infection, heterogeneous infecting inoculum, or differential host immune responses. Most recently, a so-called IFN sensitivity determining region has been described within the NS-5 region of the virus. ${ }^{162}$

Similar pretreatment factors have been analysed in the more recent combination treatment trials (see tables 2, 3). In the IFN/ribavirin combination study of Poynard and colleagues, ${ }^{144}$ logistic regression revealed five factors associated with a favourable response: genotype 2 or 3, viral load less than 2 million copies per $\mathrm{ml}$, age less than 40 years, minimal fibrosis on biopsy, and female sex (fig 1). Although the difference between 24 or 48 weeks of combination treatment barely reached significance in McHutchinson's trial, it seems that those patients with factors associated with poor response such as genotype 1 and high level viraemia will benefit most from 48 weeks of treatment. In patients infected with genotype 1 , the sustained response rate increased from $16 \%$ for 24 weeks to $28 \%$ for 48 weeks of treatment. In those patients infected with other genotypes, the response rates were equally good for $24(69 \%)$ and $48(66 \%)$ weeks of treatment. Similar findings were shown when patients were discriminated by HCV viraemia with improved sustained response rates for 48 weeks of treatment $(36 \%)$ in high level viraemia ( $>2$ million copies per $\mathrm{ml})$ compared with 24 weeks $(27 \%)$. In patients with low level viraemia, there was no benefit in prolonging treatment to 12 months (24 weeks of treatment $42 \% ; 48$ weeks of treatment $43 \%$ ). 


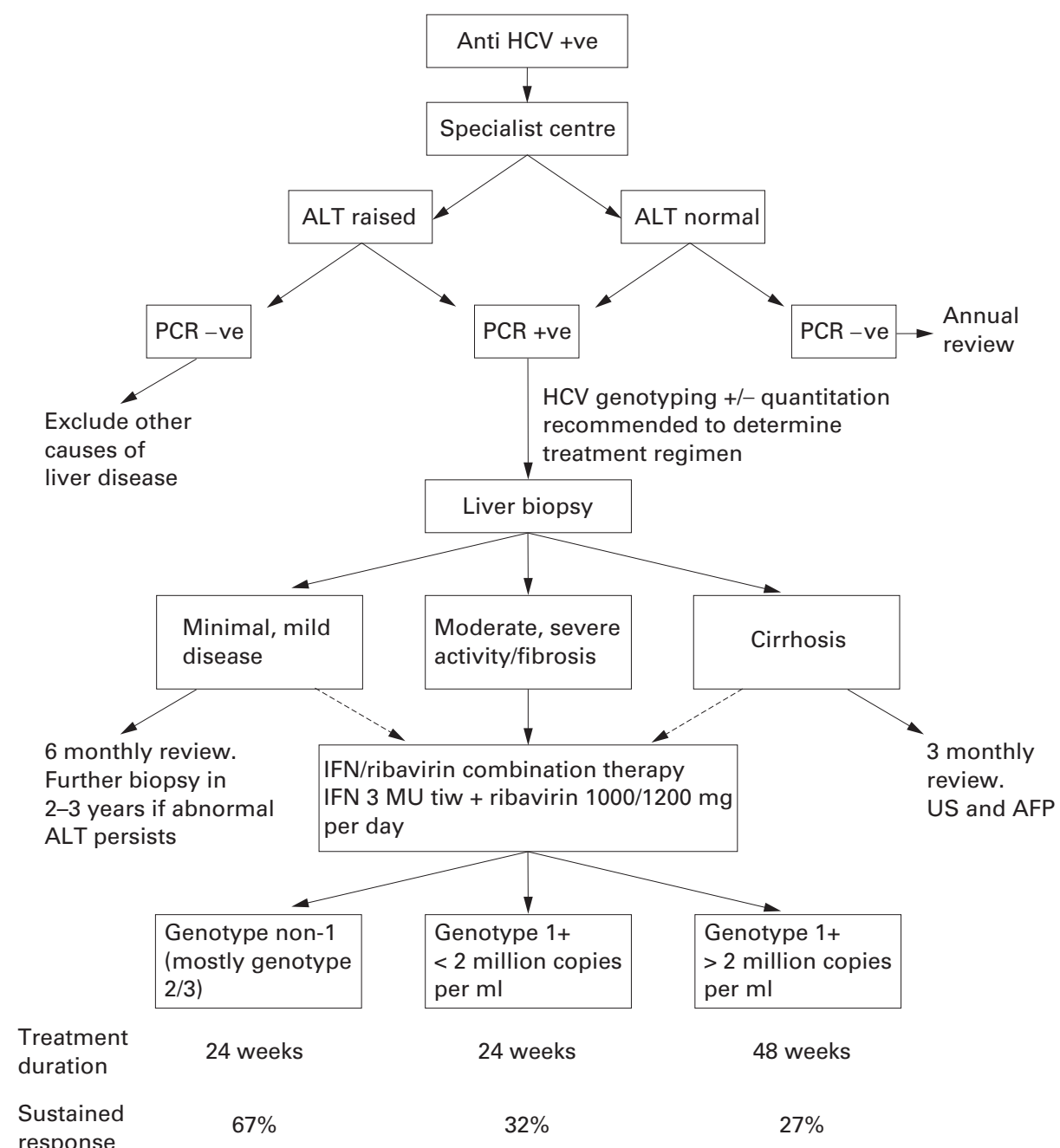

Fig 1 Hepatitis $C$ virus (HCV) algorithm. Sustained response defined as negative polymerase chain reaction (PCR) six months after treatment cessation. Data derived from Poynard and colleagues ${ }^{14}$ and McHutchinson and colleagues, ${ }^{145}$ as shown in the review by Weiland. ${ }^{177}$ IFN, interferon; ALT, alanine aminotransferase; US, ultrasound; AFP, a fetoprotein.

4.7.2 Predictors of response during treatment

The early period of treatment has also been studied to see if sustained response can be predicted. Early normalisation of ALT is a more accurate predictor of response to IFN monotherapy than any of the pretreatment factors studied above. In a study of alfa- $2 b$ IFN, Lindsay et al showed that no patient treated with $3 \mathrm{MU}$ who had not responded biochemically by week 12 responded subsequently to further treatment with IFN. ${ }^{163}$ However, a small percentage $(12 \%)$ of these patients responded to high dose IFN (10 MU) but their responses were not maintained.

Loss of HCV RNA during the initial weeks of treatment may also help predict response. In one study a positive PCR test at three months reliably predicted failure to demonstrate sustained response but a negative PCR at three months was not an accurate predictor. ${ }^{117} \mathrm{~A}$ recent study suggests that loss of HCV RNA and normalisation of ALT are similar in their ability to predict response. ${ }^{164}$ Further studies are needed to clarify the role of PCR testing at three months in determining whether to continue treatment. Future studies will also study the decline in viral load as a predictor.
- Treatment should not be withheld on the basis of genotype analysis or measurement of HCV RNA levels. (Recommendation grade $\mathrm{B}$.)

- The duration of combination treatment depends on the genotype and level of viraemia. (Recommendation grade A.)

- Patients infected with non-HCV 1 (mostly genotype 2 or 3 ) should be treated for six months irrespective of the level of viraemia. (Recommendation grade A.)

- Patients infected with genotype 1 and low level viraemia ( $<2$ million copies per $\mathrm{ml}$ ) should be treated for six months whereas 12 months of treatment is recommended for those infected with genotype 1 and high level viraemia ( $>2$ million copies per $\mathrm{ml}$ ). (Recommendation grade A.) If $\mathrm{HCV}$ quantitation is not available, treatment is recommended for 12 months in HCV 1 infected patients (Recommendation grade A.) 
Using the early treatment response is more accurate than pretreatment assessment (other than the finding of cirrhosis) and many clinicians will stop treatment or consider other treatment options for those patients failing to normalise ALT levels or who remain PCR positive at a defined point in treatment, such as at three months. This is a reasonable approach and will prevent excess costs of continuing IFN for a further nine months in patients unlikely to derive biochemical or virological sustained response. One interesting finding from the combination treatment study by McHutchinson and colleagues ${ }^{145}$ was that in at least $50 \%$ of patients with a sustained response after initial treatment with combination therapy, HCV RNA was not cleared from serum until after week 12 or 24 of treatment. The recommendation that early virological response should be used to determine further therapy needs to be evaluated in future studies of combination treatment.

- Patients unlikely to respond to IFN monotherapy can be identified at three months by persistent elevation of serum transaminase levels and the persisting presence of HCV RNA by PCR in serum. (Recommendation grade B.) If ALT levels are normal or HCV RNA negative (or both) at three months, IFN monotherapy should be continued for the full duration (12 months). (Recommendation grade $B$.) In patients with initially normal ALT levels, failure to become RNA negative at three months suggests longer treatment will be ineffective. (Recommendation grade $\mathrm{B}$.)

- The recommendation that early treatment response can be used to predict sustained response does not apply to patients receiving combination therapy. (Recommendation grade A.) In those patients receiving 12 months of IFN/ribavirin combination therapy, a positive PCR at six months is an indication to stop treatment. (Recommendation grade C.)

4.8 SIDE EFFECTS OF TREATMENT

4.8.1 Minor side effects

The majority of patients receiving IFN will report at least one side effect. Most of these are minor and do not require dose modification. The most common are flu-like symptoms including fatigue, headache, myalgia, fever, rigors, and arthralgias. These effects occur 6-8 hours after the initial injection and can be ameliorated by taking paracetomol and by dosing at night before going to bed. Often these symptoms will improve after 2-4 weeks of treatment. Ribavirin may cause non-specific symptoms of fatigue, depression, insomnia, and nausea.

Approximately $50 \%$ of patients taking IFN will report central nervous system symptoms such as irritability, depression, impaired concentration, and insomnia. Other symptoms such as gastrointestinal complaints, alopecia, and rhinorrhoea may occur.
IFN has myelosuppressive effects resulting in reduced granulocyte, platelet, and red cell counts. The reductions are usually mild and well tolerated unless there are existing haematological problems or evidence of hypersplenism, and blood counts will return to normal after therapy. Increased triglyceride levels are commonly found as is mild proteinuria, both normalising after therapy.

\subsubsection{Serious side effects}

Serious neuropsychiatric side effects to IFN can occur and include depression, paranoia, severe anxiety, and psychosis. In patients with a history of substance abuse, the psychiatric changes can lead to a disastrous relapse in alcohol or drug abuse. In some patients there is deterioration in liver function, in some cases it can be severe, which may be due to induction of an autoimmune hepatitis. These patients may have been misdiagnosed or may have an underlying autoimmune diathesis. Autoantibodies such as antinuclear antibody, smooth muscle antibody, and liver kidney microsomal should be screened for before therapy. The development of an immune hepatitis prompts withdrawal of IFN treatment.

IFN therapy can lead to the development of several types of autoantibody including antithyroid, antinuclear, and antibodies against insulin. These are usually of no significance but the development of clinical autoimmune disease, such as thyroid disease, may lead to treatment withdrawal. Other reported conditions prompted by IFN include diabetes, thrombocytopenia, haemolytic anaemia, psoriasis, vitiligo, rheumatoid arthritis, SLE-like syndromes, primary biliary cirrhosis, and sarcoidosis.

Renal lesions such as interstitial nephritis, nephrotic syndrome, and acute renal failure have been described, as have cardiovascular complications including arrhythmias, ischaemic heart disease, and cardiomyopathy. Retinopathy, hearing loss, and severe pneumonitis have also been reported.

Overall, the prevalence of serious side effects is fairly low but there seems to be a dose dependent increase in most. In Poynard et al's meta-analysis many common side effects were far commoner in patients given high dose IFN (>5 MU) compared with $3 \mathrm{MU}$, and led to dose reduction in $22 \%$ compared with $9 \%$ of patients. However, the numbers of patients stopping treatment was similar $(5 \% v 4 \%) .^{125}$ Serious or life threatening side effects occurred in $1-2 \%$ of patients.

The major adverse effect of ribavirin is haemolysis. In the combination study of Reichard et al, side effects were more common in the combination therapy group and prompted withdrawal of therapy in $7 / 50$ combination therapy patients compared with $3 / 50$ in the IFN alone group. ${ }^{143}$ In the French study, ${ }^{144}$ discontinuation of therapy for adverse events was more frequent with combination (19\%) and monotherapy (13\%) given for 48 weeks than combination given for 24 weeks (8\%). In McHutchinson's trial the drug dose had to be reduced and treatment discontinued 
more often in patients treated with combination therapy; $8 \%$ (24 week) and 21\% (48 week) discontinued for combination group compared with $9 \%$ and $14 \%$ for the IFN monotherapy group. More frequent side effects are a potentially limiting factor to combination therapy.

- Although transient or mild side effects are common during IFN monotherapy, serious toxicity requiring reduction in dose or cessation of treatment occurs in $5-10 \%$ of patients during treatment. (Recommendation grade $\mathrm{A}$.)

- Withdrawal from IFN/ribavirin combination therapy occurs more often with $10-20 \%$ of patients requiring a reduction in dose or cessation of combination therapy. (Recommendation grade A.)

4.9 RECOMMENDED TREATMENT REGIMEN AND MONITORING

Monitoring patients during therapy is extremely important, requiring regular clinical examination, psychological assessment, urinanalysis, serum chemistry, blood counts, and thyroid function tests. Pregnancy tests should be performed prior to treatment and patients advised not to conceive while on treatment and for at least six months after combination therapy.

We recommended using alfa-IFN $3 \mathrm{MU}$ three times per week for 12 months if used as monotherapy. Patients should be tested at three months and those failing to respond (biochemically and virologically) should stop therapy and be considered for further treatment trials of combination therapies. Combination therapy should be prescribed as IFN $3 \mathrm{MU}$ three times per week with ribavirin 1000 $\mathrm{mg} /$ day for patients weighing $75 \mathrm{~kg}$ or less and $1200 \mathrm{mg}$ for those weighing more than $75 \mathrm{~kg}$. Treatment should not be stopped at three months irrespective of biochemical or virological response but in those patients with treatment planned for 12 months (genotype 1) persistence of viraemia at six months may prompt treatment cessation.

Patients should be seen weekly for the first four weeks of IFN/ribavirin combination treatment so that blood counts are performed to look for haemolysis. Thereafter patients should be seen at monthly intervals until six months and then every three months until therapy is finished if treatment is given for a full year. Patients need continued support and encouragement and side effects must be monitored. At each visit full blood counts, renal, thyroid, and LFTs should be taken. Serum for PCR should be taken at three months of treatment and if possible at every three months of therapy. In patients treated with IFN monotherapy a positive PCR test of serum at three months should prompt treatment withdrawal. The response to combination therapy should be assessed by PCR testing at six months in patients with genotype 1 ; treatment should be stopped if the PCR remains positive.

Dose reductions may be necessary for side effects but if possible the course of IFN or
IFN/ribavirin should be completed. Follow up testing, with serum ALT and serum RNA, should be performed six and 12 months after treatment. A negative PCR test 24 weeks after treatment cessation defines a sustained treatment response and in the majority of cases will remain negative in prolonged follow up. We do not recommend routine follow up liver biopsy.

4.10 TREATMENT OF NON-RESPONDERS AND RELAPSERS AFTER INTERFERON MONOTHERAPY The response rate for a second course of IFN is extremely poor in patients failing to respond to an initial course of IFN (abnormal ALT at the end of therapy). In a review of 13 studies including 591 non-responders, the sustained response rates to a second course were $1-3 \% .{ }^{165}$

However, the results of a second course of IFN in patients relapsing after therapy are more encouraging. The rates of sustained response were $15 \%$ for patients receiving a second course of $3 \mathrm{MU}$ for six months, $29 \%$ in patients receiving $>3 \mathrm{MU}$ for six months, and as high as $43 \%$ in patients treated for 12 months or longer. In studies that analysed virological response, the presence of a negative PCR test at the end of the first course of treatment was highly predictive of a sustained response after retreatment. The combined analysis of five studies showed a sustained response in $56 \%$ of 145 patients rendered PCR negative at the end of the first course of treatment compared with $2.9 \%$ of 206 who remained PCR positive but with normal ALT levels at the end of the first course of therapy. ${ }^{165}$ There appears little point in retreating patients who relapse after an initial high dose IFN course as sustained response rates are low $(<5 \%)$.

More recently, IFN/ribavirin combination studies have also revealed improved response rates for a further course of combination therapy after either a failed course of IFN monotherapy or in patients who relapse after treatment. In an Italian study of 96 nonresponders, HCV RNA was undetectable at the end of treatment in $27 \%$ of patients treated with a further six month course of combination therapy compared with $7 \%$ in those treated with IFN monotherapy $(\mathrm{p}<0.05) .{ }^{166}$ However, at six months after therapy the response rate had fallen to $15 \%$. In a Spanish study the six month post therapy response was $10 \%$ for a mixed group of non-responders and relapsers. ${ }^{167}$ In another study with equal numbers of non-responders (24) and relapsers (24), $\mathrm{HCV}$ was not detectable six months after treatment in $20.8 \%$ of those treated with combination therapy compared with $4.2 \%$ treated with a further course of IFN monotherapy. ${ }^{168}$ However, in this study $25 \%$ of patients required dose reduction and $12.5 \%$ of patients were withdrawn due to intolerable side effects.

The International Hepatitis Interventional Therapy Group published their randomised study of 345 relapsers treated with a further six month course of IFN/ribavirin or IFN monotherapy. ${ }^{169}$ The primary end point was the absence of HCV RNA in serum at the end of therapy and six months after the cessation of 
therapy. At the end of treatment $82 \%$ (141/ 173 ) versus $47 \%$ ( $80 / 172)$ were PCR negative for the combination versus monotherapy groups, respectively $(\mathrm{p}<0.001)$. At six months after treatment cessation the rates of PCR negativity were $49 \%$ versus $5 \%(p<0.001)$. In this study the safety profiles of the two treatment regimens were similar, with discontinuation of therapy in $6 \%$ of the combination group and $3 \%$ of the IFN monotherapy group.

- Patients with a combined biochemical and virological response at the end of IFN monotherapy, who relapse in follow up over the next year, have a significant chance of a sustained response after further treatment with IFN/ribavirin. (Recommendation grade A.)

- Patients with a biochemical but not virological response during initial treatment with IFN monotherapy are unlikely to have a sustained response to further treatment with IFN/ribavirin. (Recommendation grade A.)

4.11 COST EFFECTIVE ANALYSIS

The long term benefit of antiviral therapy is difficult to prove currently due to the relatively long natural history of $\mathrm{HCV}$ and the fact that patients need to be followed up for many years after successful viral eradication. So far studies have shown that sustained viral response (that is, negative PCR at 24 weeks after treatment cessation) is maintained for several years and that these viral responses are accompanied by improvements in histological scores of necroinflammation. It seems reasonable to suggest that sustained virological responders will derive long term benefit and will not progress to end stage liver disease as frequently as those failing to respond. Those studies showing reduced rates of HCC in treated patients support this view although the results of further studies are needed to clarify this issue. While monitoring and treating patients costs money, far greater health care related costs are incurred when patients develop cirrhosis and its complications, including variceal bleeding or HCC. ${ }^{170}$ However, disease progression is not universal and treatment may be unnecessary in patients who do not develop $\mathrm{HCV}$ related complications in their lifetime.

Treatment with IFN and ribavirin is associated with high initial costs, and studies need to address the relative cost effectiveness of treatment in terms of years of life gained, quality of life, indirect costs including loss of productivity for sick patients, and projected health care costs for the management of the complications of chronic HCV such as the development of cirrhosis and HCC.

The costs of implementing a management policy involve staff, laboratory, and drug costs. Patients attending clinics regularly will use medical, nursing, secretarial, and other staff time, although many will attend general medical or perhaps gastroenterological/hepatological clinics. In larger centres there may be specialist clinics with attending clinical nurse specialists.
The laboratory costs will include routine blood testing, analysis of liver biopsy specimens, and PCR testing (cost $\sim £ 40-50$ ), genotype testing and viral load measures. The cost of one year's IFN at $3 \mathrm{MU}$ three times weekly is approximately $£ 2500$ rising to $£ 5000$ for six months' combination therapy and $£ 10000$ for those requiring 12 months of IFN/ribavirin combination treatment.

Economic analysis must play a part in planning the management of HCV but due to the long course of the disease many of the important questions about cost effectiveness of therapy cannot be answered. Instead, researchers have made use of modelling using Markov simulations to predict the likely outcomes and thus assess the impact of therapy, such as the one produced by Dusheiko and Roberts. ${ }^{171}$ This model analysed two hypothetical groups of patients, one treated and one untreated, followed for 30 years. The costs estimated were only those direct costs associated with hospital follow up and treatment, and those indirect costs including quality of life, time off work, and so on were not assessed. Thus the value of intervention in this model was underestimated.

Not surprisingly the costs in the treated group were higher in the first year while treatment is given and follow up is intense. However, in subsequent years the costs in the treated cohort were less than the untreated group because fewer entered the later expensive stages of the disease. Although IFN monotherapy is expensive it is not out of line with many other health care interventions, with a discounted cost per year of life saved ranging from $£ 2142$ to $£ 8555$. This compares with figures of $£ 32000$ for cholesterol reduction in patients with coronary heart disease, ${ }^{172} £ 6315$ for home dialysis, ${ }^{173}$ and $£ 3135$ for enalapril treatment of chronic heart failure. ${ }^{174}$

The model was based on information available in the early 1990s and as more data become available about response to treatment and pathogenicity of the various groups it should be possible to produce models that more accurately reflect disease patterns. Wong et al have assessed the cost effectiveness of IFN/ribavirin combination versus IFN monotherapy using recent controlled trial data. ${ }^{175}$ In comparison with 12 months of IFN monotherapy, the model indicated that combination therapy for six or 12 months should increase life expectancy and is cost effective with a marginal cost effectiveness ratio of $\$ 2100$ and $\$ 2300$ per discounted quality adjusted life year gained, respectively. The Scottish Health Purchasing Information Centre have developed a spreadsheet that can be used to estimate costs and is available from the group. ${ }^{176}$ Their cost per life year saved estimates were $£ 3000$ (1000 $\mathrm{mg}$ ribavirin) and $£ 3500$ (1200 $\mathrm{mg}$ ribavirin) for six months and $£ 6000$ and $£ 6700$ for 12 months compared with no treatment. Once again these figures are within the range of other accepted NHS activities. Any increase in targeting therapy to particular groups, such as genotypes, must be balanced with the costs of screening procedures and the sensitivity and specificity of these procedures. Later delivery 


\section{Summary of recommendations}

Patients infected with HCV should be referred to a clinician with a particular interest in the infection. Patients must have access to adequate counselling from a health carer with knowledge and experience of chronic HCV infection. All patients must have access to the appropriate diagnostic and therapeutic options available in the management of $\mathrm{HCV}$ infection.

Where possible, a judgement is made on the quality of information used to generate the guidelines. Categories of evidence are classified: A-RCTs, meta-analyses, or systematic reviews;

B - prospective, retrospective, or cross sectional studies;

C-expert opinion.

\section{Guideline recommendations}

DIAGNOSIS

- Patients with suspected HCV infection should be tested for anti-HCV by an up to date (currently third generation) ELISA test. (Recommendation grade C.)

- All patients with positive antibody tests and those patients thought to be at risk of $\mathrm{HCV}$ infection despite negative or indeterminate serological tests should undergo PCR testing of serum. A positive result confirms current viraemia whereas a negative test suggests non-viraemic infection, transient absence of viraemia or recovered infection, a level of viraemia below the detection limit of the assay, or may reflect a non-specific ELISA result. (Recommendation grade B.)

- Patients with positive ELISA but negative PCR should therefore be tested with recombinant immunoblot assay to confirm antibody status. (Recommendation grade B.)

- A qualitative PCR test is recommended in immunodeficient patients with suspected HCV infection. (Recommendation grade B.)

- The results of routine liver tests correlate poorly with both necroinflammatory and fibrosis scores found on liver biopsy. (Recommendation grade $\mathrm{B}$.)

- Liver biopsy is valuable for assessing status of liver inflammation, potential progression of fibrosis, and the presence or absence of cirrhosis. To clarify these, and to assess suitability for treatment, liver biopsy is recommended for patients found to be viraemic, whether or not liver function tests are abnormal. Standard histological scoring systems by a suitably experienced pathologist should be used to encourage uniformity of histological reports. The risks and benefits of liver biopsies must be fully discussed with the patient. (Recommendation grade B.)

- Measurement of HCV RNA concentrations in serum and determination of HCV genotype are recommended and should be used to determine the duration of treatment (see later). (Recommendation grade A.)

COUNSELLING REGARDING TRANSMISSION

- Patients should be counselled on the implications of HCV positivity and advised on the risks of infectivity.

- the natural history is slowly progressive (median time to cirrhosis 28-32 years). (Recommendation grade A.)

-HCV positive patients should not donate blood, organs, tissues, or semen. (Recommendation grade C.)

- the risk of sexual transmission is small (maximum 5\% but possibly much less). (Recommendation grade B.) There is insufficien evidence to firmly recommend barrier contraception in stable monogamous relationships but is strongly advised for $\mathrm{HCV}$ infected patients with multiple sexual partners. (Recommendation grade C.)

-transmission from mother to child is rare (maximum of $6 \%$ ) but transmission rates are higher in HIV positive mothers. (Recommendation grade B.)

-breast feeding is not contraindicated. (Recommendation grade C.)

-household contacts should avoid third party contact with blood by not sharing toothbrushes and razors, and by covering open wounds. (Recommendation grade C.)

-standard precautions for the prevention of transmission to medical personnel and patients is mandatory in health care settings. (Recommendation grade C.)

-needle exchange programmes in drug addicts may help reduce parenterally transmitted infection. (Recommendation grade C.)

- Current IVDUs should not be treated although in selected cases ex-IVDUs taking regular oral methadone may be considered for treatment. (Recommendation grade C.)

TREATMENT - GENERAL MEASURES

- Patients should be advised that excess alcohol consumption ( $>50$ $\mathrm{g} /$ day) appears to hasten the progression of disease. (Recommendation grade $\mathrm{B}$.)

- Consideration should be given to entering patients with established cirrhosis into surveillance programmes for HCC, if their general state of health is sufficiently good that emerging cancers could be appropriately treated. (Recommendation grade C.)

- Patients must be screened for their suitability to receive IFN and ribavirin, with criteria which includes proven viraemia and abnormal liver histology. (Recommendation grade C.)

- IFN and ribavirin are currently the only licensed treatments for HCV in the UK.
- IFN/ribavirin combination is the treatment of choice for IFN naive patients. (Recommendation grade A.)

- IFN/ribavirin combination is also recommended for those patients relapsing after IFN monotherapy. (Recommendation grade A.)

- IFN monotherapy should be considered for those patients in whom ribavirin is contraindicated. (Recommendation grade C.)

- The role of pegylated interferon remains unknown. (Recommendation grade C.)

TREATMENT - INTERFERON MONOTHERAPY

- We recommend IFN monotherapy should be initiated at a dose of 3 MU three times per week by injection. (Recommendation grade B.)

- IFN monotherapy should be continued for 12 months unless there is evidence of failure to respond (see below). (Recommendation grade B.)

- There is no evidence to suggest that one type of alfa-IFN is superior to another (alfa-2b, alfa-2a, alfa-n1, and consensus interferon (CIFN)). (Recommendation grade $\mathrm{B}$.)

TREATMENT-INTERFERON/RIBAVIRIN COMBINATION THERAPY

- Recent results of large randomised controlled studies have shown improved response rates for IFN/ribavirin combination therapy in IFN naive and relapsers compared with IFN monotherapy. (Recommendation grade A.)

- Combination therapy consists of IFN at standard doses (usually $3 \mathrm{MU}$ three times per week) with ribavirin $1000 \mathrm{mg}$ /day for patients weighing $75 \mathrm{~kg}$ or less and $1200 \mathrm{mg}$ for those weighing more than $75 \mathrm{~kg}$. (Recommendation grade A.)

- In viraemic patients, the decision to offer treatment should be influenced by the histological findings. (Recommendation grade B):

- treatment can be reasonably withheld in patients with mild disease (see text) but they should be followed to see if there is evidence of progressive liver disease by the use of repeated biopsy after an interval. (Recommendation grade $\mathrm{C}$.)

- treatment should be offered to those patients shown to have moderate disease. (Recommendation grade C.)

- cirrhotic patients respond less well to IFN monotherapy but sustained responses have improved with IFN/ribavirin combination treatment. There is no conclusive evidence that treatment in this group of patients delays progression of liver disease or the development of HCC. (Recommendation grade B.)

- Treatment should not be withheld on the basis of genotype analysis or the measurement of HCV RNA levels. (Recommendation grade B.)

- The duration of combination treatment depends on the genotype and level of viraemia. (Recommendation grade A.)

- Patients infected with non-HCV 1 (mostly genotype 2 or 3 ) should be treated for six months irrespective of the level of viraemia. (Recommendation grade A.)

- Patients infected with genotype 1 and low level viraemia $(<2$ million copies per ml) should be treated for six months whereas 12 months' treatment is recommended for those infected with genotype 1 and high level viraemia ( $>2$ million copies per $\mathrm{ml}$ ). (Recommendation grade A.) If HCV quantitation is not available treatment is recommended for 12 months in HCV 1 infected patients. (Recommendation grade A.)

- Patients unlikely to respond to IFN monotherapy can be identified at three months by persistent elevation of serum transaminase levels and the persisting presence of HCV RNA by PCR in serum. (Recommendation grade B.) If ALT levels are normal or HCV RNA negative (or both) at three months, treatment should be continued for the full duration (12 months). (Recommendation grade B.) In patients with initially normal ALT levels, failure to become RNA negative at three months suggests longer treatment will be ineffective. (Recommendation grade B.)

- The recommendation that early treatment response can be used to predict sustained response does not apply to patients receiving combination therapy. (Recommendation grade A.) In those patients receiving 12 months of IFN/ribavirin combination therapy a positive PCR at six months is an indication to stop treatment. (Recommendation grade C.)

- Although transient or mild side effects are common during IFN monotherapy, serious toxicity requiring reduction in dose or cessation of treatment occurs in $5-10 \%$ of patients during treatment. (Recommendation grade $\mathrm{A}$.)

- Withdrawal from IFN/ribavirin combination therapy occurs more often with $10-20 \%$ of patients requiring a reduction in dose or cessation of combination therapy. (Recommendation grade A.)

- Patients with a combined biochemical and virological response at the end of IFN monotherapy, who relapse in follow up over the next year, have a significant chance of a sustained response after further treatment with IFN/ribavirin. (Recommendation grade A.)

- Patients with a biochemical but not virological response during initial treatment with IFN monotherapy are unlikely to have a sustained response to further treatment with IFN/ribavirin. (Recommendation grade A.)

- There is continuing development in the treatment of patients with $\mathrm{HCV}$ infection. In particular, the role of pegylated interferon and re-use of weight adjusted doses of interferon will shortly be established. The guidelines will need regular and frequent review. (Recommendation grade C.) 
of therapy to a group of progressors is likely to be more cost effective, as the benefits are likely to be felt sooner.

More information is needed and the results of future studies should include indirect costs to patients, primary care, and community services, and improved outcome measures such as quality of life measures should be incorporated into the analysis.

\subsection{Future research}

There is a pressing need for further research into several important areas of $\mathrm{HCV}$ infection. The most important areas of future research are: determination of the natural history of $\mathrm{HCV}$ infection in the UK with the study of the cohort identified in the "lookback study", multivariate analysis of current data to analyse factors predictive of response to treatment, the development of new antiviral therapies, prolonged follow up of those patients already treated in trials to determine the long term improvements in terms of liver disease progression, and finally determining whether screening for HCC is beneficial in the HCV infected patient population. Future research will also focus on the development of more effective and better tolerated therapies such as pegylated IFN and also on the development of treatment in special situations such as acute HCV, mild hepatitis, and in advanced liver disease.

- There is continuing development in the treatment of patients with $\mathrm{HCV}$ infection. In particular, the role of pegylated interferon and re-use of weight adjusted doses of interferon will shortly be established. The guidelines will need regular and frequent review. (Recommendation grade C.)

\subsection{Appendix}

Thank you to the following for their contribution to the development of the guidelines: Dr Miles Allison, Dr Koye Balogan, Professor Maggie Bassendine, Dr William Bird, $\mathrm{Mr}$ Christopher Buckler, Professor Duncan ColinJones, Dr Brian Cooper, Professor Geoffrey Dusheiko, Professor Elwyn Elias, Ms Heather Gibson, Dr Rob Goldin, Ms Kate Grainger, Dr Maggie Harding, Dr Sally Hargreaves, Professor Peter Hayes, Dr Robert Heading, Dr Mike Hellier, Professor Humphrey Hodgson, Dr Guy Houghton, Nigel Hughes, Professor Derek Jewell, Dr Martin Lombard, Ms Janet McCulloch, Dr Mary Ramsay, Dr Jenny Roberts, Dr William Rosenberg, Dame Sheila Sherlock, Professor Peter Scheuer, Professor Richard Tedder, Dr Christopher Tibbs, Professor Howard Thomas, Dr Patrick Wheeler, Mr Basil Williams, and Professor Roger Williams.

\subsection{References}

1 Choo Q-L, Weiner A, Overby L, et al. Hepatitis C virus: The major causative agent of viral NANB hepatitis. Br Med Bull 1990;46:423-41.

2 Kuo G, Choo Q-L, Alter H, et al. An assay for circulating antibodies to a major etiologic virus of human non-A non-B hepatitis. Science 1989;244:362-4. 3 Esteban J, Viladomiu L, Gonzalez A, et al. Hepatitis C virus antibod.

4 Alter H, Purcell R, Shih J, et al. Detection of antibody to hepatitis $\mathrm{C}$ virus in prospectively followed transfusion recipients with acute and chronic non-A, non-B hepatitis. N Engl F Med 1989;321:1494-500.

5 Roggendorf M, Deinhadt F, Rasslofer R, et al. Antibodies to HCV. Lancet 1989;334:324-5.

6 Van Der Poel C, Reesing H, Lelie P, et al. Anti-hepatitis C antibodies and NANB post-transfusion hepatitis in Netherlands. Lancet 1989;ii:297-8.

7 Weiner A, Kuo G, Bradley D, et al. Detection of hepatitis C sequences in non-A, non-B hepatitis. Lancet 1990;335:1-3.

8 Alter MJ, Margolis HS, Krawczynski K, et al. The natural history of community-acquired hepatitis $C$ in the United States. N Engl f Med 1992;327:1899-905.

9 Mutimer D, Harrison R, O'Donnell K, et al. Hepatitis C Mutimer D, Harrison R, O'Donnell K, et al. Hepatitis C
virus infection in the asymptomatic British blood donor. 7 Viral Hepat 1995;2:47-53.

10 Delaporte E, Thiers V, Dazza M, et al. High level of hepatiis C endemicity in Gabon, equatorial Africa. Trans $R$ Soc Trop Med 1993;87:636-7.

11 Saeed A, Al-Admawi A, Al-Rasheed A, et al. Hepatitis C virus infection in Egyptian volunteer blood donors in Riyadh. Lancet 1991;338:459-60.

12 El-Ahmady O, Halim A, Mansour O, et al. Incidence of hepatitis C virus in Egyptians. $\mathcal{F}$ Hepatol 1994;21:687.

13 Zuckerman A. The elusive hepatitis $\mathrm{C}$ virus. BMf 1989;299:871-3.

14 Allain J-P, Dailey S, Laurian Y, et al. Evidence for persistent hepatitis $\mathrm{C}$ virus (HCV) infection in haemophiliacs. $f$ Clin Invest 1991;88:1672-9.

15 Di Bisceglie A, Goodman Z, Ishak K, et al. Long-term clinical and histological follow up of chronic posttransfusion hepatitis. Hepatology 1991;14:969-74.

16 Tremolada F, Casarin C, Alberti A, et al. Long-term follow-up of non-A, non-B (type C) post-transfusion hepatitis. F Hepatol 1992;16:273-81.

17 Gilli P, Moretti M, Soffritti S, et al. Anti-HCV positive patients in dialysis units. Lancet 1990;336:243-4.

18 Mondelli MU, Cristina G, Filice G, et al. Anti-HCV positive patients in dialysis units. Lancet 1990;336:244.

19 Pereira B, Milford E, Kirkman R, et al. Transmission of hepatitis $\mathrm{C}$ virus by organ transplantation. $N$ Engl $\mathcal{F}$ Med 1991;325:454-60

20 Kiyosawa K, Sodeyama T, Tanaka E, et al. Hepatitis C in hospital employees with needle stick injuries. Ann Intern Med 1991;115:367-9.

21 Zuckermen J, Clewley G, Griffiths P, et al. Prevalence of hepatitis $\mathrm{C}$ antibodies in clinical health-care workers. Lanhepatitis $C$ antibodies in

22 Melbye M, Biggar R, Wantzin P, et al. Sexual transmission of hepatitis C virus: cohort study (1981-9) among European hepatitis C virus: cohort study (1981-9) am

23 Tedder R, Gilson R, Briggs M, et al. Hepatitis C virus: evidence for sexual transmission. BMF 1991;302:1299-302.

24 Hess G, Massing A, Rossol S, et al. Hepatitis C virus and sexual transmission. Lancet 1989;334:987.

25 Wright $\mathrm{T}$, Hollander $\mathrm{H}, \mathrm{Pu} \mathrm{X}$, et al. Hepatitis $\mathrm{C}$ in HIV-infected patients with and without AIDS: Prevalence and relationship to patient survival. Hepatology 1994;20: 1152-5.

26 Bresters D, Mauser-Bunschoten EP, Reesink HW, et al. Sexual transmission of hepatitis C virus. Lancet 1993;342: $210-11$.

27 Gordon S, Elloway R, Long J, et al. The pathology of hepatitis $\mathrm{C}$ as a function of mode of transmission: blood transfusion vs intravenous drug use. Hepatology 1993;18:133843.

28 Hsu H, Wright T, Luba D, et al. Failure to detect hepatitis C virus genome in human secretions with the polymerase chain reaction. Hepatology 1991;14:763-7.

29 Scaraggi FA, Lomuscio S, Perricci A, et al. Intrafamilial and sexual transmission of hepatitis C virus. Lancet 1993;342: 1300-1

30 Chayama K, Kobayashi M, Tsubota A, et al. Molecular analysis of intraspousal transmission of hepatitis $\mathrm{C}$ virus. $\mathcal{F}$ Hepatol 1995;22:431-9.

31 Akahane Y, Kojima M, Sugai Y, et al. Hepatitis C virus infection in spouses of patients with type C chronic liver disease. Ann Intern Med 1994;120:748-52.

32 Kao J-H, Chen P-J, Lei M-Y, et al. Sexual transmission of HCV. Lancet 1993;342:626.

33 Mesquita P, Granato C, Castelo A. Risk factors associated with hepatitis $\mathrm{C}$ virus (HCV) infection among prostitutes with hepatitis $\mathrm{C}$ virus (HCV) infection among prostitutes zil. f Med Virol 1997;51:338-43.

34 Giovannini M, Tagger A, Ribero ML, et al. Maternal-infant transmission of hepatitis $C$ virus and HIV infections: a possible interaction. Lancet 1990;335:1166.

35 Ohto H, Terazawa S, Sasaki N, et al. Transmission of hepatitis $\mathrm{C}$ virus from mothers to infants. $N$ Engl $f \mathrm{Med}$ 1994;330:744-50.

36 Zanetti A, Tanzi E, Paccagnini S, et al. Mother-to-infant transmission of hepatitis C virus. Lancet 1995;345:289-91.

37 Meisal H, Reip A, Faltus B, et al. Transmission of hepatitis $\mathrm{C}$ virus to children and husbands by women infected with contaminated anti-D immunoglobulin. Lancet 1995;345: 1209-11.

38 Manzini P, Saracco G, Cerchier A, et al. Human immunodeficiency virus infection as risk factor for mother to child hepatitis $C$ virus transmission; persistence of antihepatitis $C$ virus in children is associated with the mother's 

anti-hepatitis C virus immunoblotting pattern. Hepatology
1995;21:328-32.

39 Ogasawara S, Kage M, Kosai K-I, et al. Hepatitis C virus RNA in saliva and breastmilk of hepatitis C carrier mothers. Lancet 1993;341:561

40 Liou T-C, Chang T-T, Young K-C, et al. Detection of HCV RNA in saliva, urine, seminal fluid and ascites. 7 Med Viro 1992;37:197-202.

41 Wang JT, Wang TH, Sheu JC, et al. Hepatitis C virus RNA in saliva of patients with posttransfusion hepatitis and low efficiency of transmission among spouses. $7 \mathrm{M}$ Med Virol 1992;36:28-31.

42 Abe K, Kurata T, Sugitani M, et al. Experimental transmission of NANB hepatitis by saliva. F Infect Dis $1987 ; 155$ : 1078-9.

43 Brackmann S, Gerritzen A, Oldenburg J. Search for intrafamilial transmission of hepatitis C virus in haemophilia patients. Blood 1993;81:1077-82.

44 Buscarini E, Tanzi E, Zanetti A. High prevalence of antibodies to hepatitis $\mathrm{C}$ virus among family members of patients with anti-HCV positive chronic liver disease. Scand $\mathcal{F}$ Gastroenterol 1993;28:343-6.

45 Wright T, Hsu H, Donegan E, et al. Hepatitis C virus not found in fulminant non-A, non-B hepatitis. Ann Intern Med 1991;115:111-12.

46 Fagan E, Harrison T. Exclusion in liver by polymerase chain reaction of hepatitis $\mathrm{B}$ and $\mathrm{C}$ viruses in acute liver failure attributed to sporadic non-A, non-B hepatitis. 7 Hepato 1994;21:587-91.

47 Weltman M, Brotodihardjo A, Crewe E, et al. Coinfection with hepatitis $\mathrm{B}$ and $\mathrm{C}, \mathrm{C}$ and $\mathrm{d}$ viruses results in severe chronic liver disease and responds poorly to interferon- $\alpha$ treatment. F Viral Hepatitis 1995;2:39-45.

48 Seeff LB, Buskell-Bales Z, Wright EC, et al. Long-term mortality after transfusion-associated non-A, non-B hepatimortality after transfusion-associated
tis. N Engl F Med 1992;327:1906-11.

49 Tong M, El-Farra N, Reikes A, et al. Clinical outcomes after transfusion-associated hepatitis C. N Engl f Med 1995;332 1463-6.

50 Yuki N, Hayashi N, Kamada T. HCV viraemia and liver injury in symptom-free blood donors. Lancet 1993;342 444 .

51 Pozzato G, Moretti M, Franzin F, et al. Severity of liver disease with different HCV clones. Lancet 1991;338:509.

52 Honda M, Kaneko S, Sakai A, et al. Degree of diversity of hepatitis $\mathrm{C}$ virus quasispecies and progression of liver disease. Hepatology 1994;20:1144-51.

53 Noda K, Yoshihara H, Suzuki K, et al. Progression of type C chronic hepatitis to liver cirrhosis and hepatocellular carcinoma - its relationship to alcohol drinking and the age of transfusion. Alcohol Clin Exp Res 1996;2:95-100A.

54 Bjoro K, Froland S, Yun Z, et al. Hepatitis C infection in patients with primary hypogammaglobulinaemia after treatment with contaminated immune globulin. $N$ Engl $\mathcal{F}$ Med 1994;331:1607-11.

55 Nalpas B, Thiers V, Pol S, et al. Hepatitis C viremia and anti-HCV antibodies in alcoholics. F Hepatol 1992;14:3814.

56 Takase S, Tsutsumi M, Kawahara $\mathrm{H}$, et al. The alcoholaltered liver membrane antibody and hepatitis $\mathrm{C}$ virus infection in the progression of alcoholic liver disease. Hepainfection in the prog

57 Martin P, Di Bisceglie AM, Kassianides C, et al. Rapidly progressive non-A, non-B hepatitis in patients with human immunodeficiency virus infection. Gastroenterology 1989; 97:1559-61.

58 Poynard T, Bedossa P, Opolon P, et al. Natural history of liver fibrosis progression in patients with chronic hepatitis C. Lancet 1997;349:825-32.

59 Fattovich G, Giustina G, Degos F, et al. Morbidity and mortality in compensated cirrhosis C: a retrospective follow-up study of 384 patients. Gastroenterology 1997;112: 463-72.

60 Lunel F. Hepatitis C virus and autoimmunity: fortuitous association or reality? Gastroenterology 1994;107:1550-5.

61 Disdier P, Harle J-R, Weiller, P-J. Cryoglobulinaemia and hepatitis C infection. Lancet 1991;338:1151-2.

62 Bichard P, Ounanian A, Girard M, et al. High prevalence of hepatitis C virus RNA in the supernatant and the croprecipitate of patients with essential and secondary type
II mixed cryoglobulinaemia. F Hepatol 1994;21:58-63.

63 Marcellin P, Descamps V, Martinot-Peignoux M, et al. Cryoglobulinaemia with vasculitis associated with hepatitis C virus infection. Gastroenterology 1993;104:272-7.

64 Silva $\mathrm{M}, \mathrm{Li} \mathrm{X}$, Cheinquer $\mathrm{H}$, et al. HCV-associated idiopathic thrombocytopenic purpura (ITP). Gastroenterolidiopathic thrombocy

65 Bruix J, Calvet X, Costa J, et al. Prevalence of antibodies to hepatitis C virus in Spanish patients with hepatocellular

66 Pares A, Barrera J, Caballeria J, et al. Hepatitis C virus antibodies in chronic alcoholic patients: association with severity of liver injury. Hepatology 1990;12:1295-9.

67 Oshita M, Hayashi N, Kasahara H, et al. Increased serum hepatitis $\mathrm{C}$ virus RNA levels among alcoholc patients with chronic hepatitis C. Hepatology 1994;20:1115-20.

68 Colombo M, Choo Q-L, Del Ninno E, et al. Prevalence of antibodies to hepatitis $C$ virus in Italian patients with hepatocellular carcinoma. Lancet 1989;334:1006-9.

69 Kew M, Houghton M, Choo Q-L, et al. Hepatitis C virus antibodies in southern African blacks with hepatocellular carcinoma. Lancet 1990;335:873-4.
70 Levrero M, Tagger A, Balsano C, et al. Antibodies to hepatitis $\mathrm{C}$ virus in patients with hepatocellular carcinoma. $\mathcal{F}$ Hepatol 1991;12:60-3.

71 Kew M, Yu M, Kedda M, et al. The relative roles of hepatitis $\mathrm{B}$ and $\mathrm{C}$ viruses in the etiology of hepatocellular carcinoma in southern African Blacks. Gastroenterology 1997;112:184-7.

72 Yamauchi M, Nakahara M, Maezawa Y, et al. Prevalence of hepatocellular carcinoma in patients with alcoholic cirrhosis and prior exposure to hepatitis C. Am $\mathcal{F}$ Gastroenterol 1993;88:39-43.

73 Nishiguchi S, Kuroki T, Nakatani S, et al. Randomised trial of effects of interferon- $\alpha$ on incidence of hepatocellular carcinoma in chronic active hepatitis $\mathrm{C}$ with cirrhosis. Lancet 1995;346:1051-5.

74 Choo Q-L, Kuo G, Weiner A, et al. Isolation of a cDNA clone derived from a blood-borne viral hepatitis genome. Science 1989;244:359-62.

75 Houghton M, Choo Q, Kuo G. Chiron Corporation. Eur Patent App 88310922. 5. Publication number 0318216, 1988.

76 Barrera J, Prancis B, Ercilla G, et al. Improved detection of anti-HCV in post-transfusion hepatitis by a third generation ELISA. Vox Sang 1995;68:15-18.

77 Busch M, Tobler L, Francis B. Re-instatement of donors who test false-positive in second generation hepatitis C virus enzyme immunoassay should await availability of licensed third-generation tests. Transfusion 1994;34:130-4.

78 Courouce A-M, Bouchardeau F, Girault A, et al. Significance of NS3 and NS5 antigens in screening for HCV antibody. Lancet 1994;343:853-4.

79 Beach MJ, Meeks EL, Mimms LT, et al. Temporal relationships of hepatitis C virus RNA and antibody responses following experimental infection of chimpanzees. $\mathcal{f} \mathrm{Med}$ Virol 1992;36:226-37.

80 Hilfenhaus J, Krupka U, Nowak T, et al. Follow-up of hepatitis $C$ virus infection in chimpanzees: determination of viraemia and specific humoral immune response. $f \mathrm{Gen}$ Virol 1992;73:1015-19.

81 McHutchinson J, Person J, Govindarajan S, et al. Improved detection of hepatitis $\mathrm{C}$ virus antibodies in high-risk populations. Hepatology 1992;15:19-25.

82 Yuki M, Hayashi N, Hagiwara $\mathrm{H}$, et al. Improved serodiagnosis of chronic hepatitis C in Japan by a secondVirol 1992;37:237-40.

83 Yuki N, Hayashi N, Kamada T. Detection of HCV infection with second-generation assays. Lancet 1993;341:1216.

84 Dourakis S, Brown J, Kumar U, et al. Serological response and detection of viraemia in acute hepatitis $C$ virus infection. F Hepatology 1992;14:370-6.

85 Follett EAC, Dow BC, McOmish F, et al. HCV confirmatory testing of blood donors. Lancet 1991;338:1024.

86 Irving WL, Day S, Eglin RP, et al. HCV and PCR negativity. Lancet 1992;339:1425.

87 Nakatsuji Y, Matsumoto A, Tanaka E, et al. Detection of $\mathrm{HCV}$ infection by four diagnostic systems: first-generation and second-generation enzyme-linked immunosorbent assay, second-generation recombinant immunoblot assay and nested polymearse chain reaction. Hepatology 1992;16: $300-5$.

$88 \mathrm{Li}$ XM, Reddy KR, Jeffers LJ, et al. Indeterminate hepatitis C. Lancet 1993;341:835.

89 Irving WL, Day S, Eglin RP, et al. Hepatitis C in blood donors. Lancet 1993;341:835-6.

90 Wicki AN, Joller-Jemelka H. Indeterminate hepatitis C. Lancet 1993;341:1534.

91 Allain J-P, Rankin A, Kuhns MC, et al. Clinical importance of HCV confirmatory testing in blood donors. Lancet 1992;339:1171-2.

92 Halfon P, Rousseau S, Tamalet C, et al. Indeterminate second-generation hepatitis $\mathrm{C}$ recombinant immunoblot test: Detection of hepatitis $C$ virus infection by polymerase chain reaction. F Infect Dis 1992;166:449.

93 Pawlotsky J, Fleury A, Deforges L, et al. Highly positive c22-3 "indeterminate" second generation RIBA: resolution by third generation RIBA and HCV RNA PCR. $f$ Hepatol 1993;18:86A.

94 Martinot-Peignoux M, Marcellin P, Branger M, et al. HCV infection assessed with third generation anti-HCV testing and polymerase chain reaction. F Hepatol 1993;18:S146.

95 Lamoril J, Lunel F, Laurent-Puig P, et al. Indeterminate third generation recombinant immunoblot assay in hepatitis $C$ virus infection. F Hepatol 1994;21:133-4.

96 Garson JA, Ring C, Tuke P, et al. Enhanced detection by PCR of hepatitis C virus RNA. Lancet 1990;336:878-9.

97 Nguyen T, Sedghi-Vaziri A, Wilkes L, et al. Fluctuations in viral load (HCV RNA) are relatively insignificant in untreated patients with chronic HCV infection. F Viral Hepatol 1996;3:75-8.

98 Alberti A, Morsica G, Chemello L, et al. Hepatitis C viraemia and liver disease in symptom-free individuals with anti-HCV. Lancet 1992;340:697-8.

99 Haber M, West A, Haber A, et al. Relationship of aminotransferases to liver histological status in chronic hepatitis C. Am f Gastroenterol 1995;90:1250-7.

100 Esteban J, Lopez-Talavera J, Genesca J, et al. High rate of infectivity and liver disease in blood donors with antibodies to HCV. Ann Intern Med 1991;115:443-9.

101 Alberti A, Morsica G, Chemello L, et al. Hepatitis C viraemia and liver disease in symptom-free individuals with anti-HCV. Lancet 1992;340:697-8. 
102 Cammell G, Younossi Z, Carey W. The utility of liver biopsy in diagnosis of hepatitis C (abstract). Gastroenterol biopsy in diagnosis of
ogy 1997;112:A1236.

103 Kumar U, Thomas H, Monjardino J. Serum HCV RNA levels in chronic HCV hepatitis measured by quantitative PCR assay; correlation with serum AST. 7 Virol Methods 1994;47:95-102.

104 Haff L. Improved quantitative PCR using nested primers. PCR Methods Appl 1994;3:332-7.

105 Wiesner R, Beinbrech B, Ruegg J. Quantitative PCR. Nature 1993;366:416.

106 Simmonds P, McOmish F, Yap PL, et al. Sequence variability in the 5 ' non-coding region of hepatitis $C$ virus:
identification of a new virus type and restrictions on identification of a new virus type and restis
sequence diversity. F Gen Virol 1993;74:661-8.

107 Cha T-A, Beall E, Irvine B, et al. At least five related, but distinct, hepatitis C viral genotypes exist. Proc Natl Acad Sci USA 1992;89:7144-8.

108 Bukh J, Purcell RH, Miller RH, et al. Sequence analysis of the 5 ' noncoding region of hepatitis $\mathrm{C}$ virus. Proc Natl Acad Sci USA 1992;89:4942-6.

109 Simmonds P, Holmes E, Cha T-A, et al. Classification of hepatitis $\mathrm{C}$ virus into six major genotypes and a series of subtypes by phylogenetic analysis of the NS -5 region. $7 \mathrm{Gen}$ Virol 1993:74:2391-9.

110 Simmonds P, Rose KA, Graham S, et al. Mapping of serotype-specific, immunodominant epitopes in the NS-4 region of hepatitis $\mathrm{C}$ virus (HCV): use of type-specific peptides to serologically differentiate infections with

111 Bukh J, Purcell R, Miller R. At least 12 genotypes of hepatitis $C$ virus predicted by sequence analysis of the putative E1 gene of isolates collected worldwide. Proc Natl Acad Sci E1 gene of isolates colle

112 Simmonds P, Smith DB, McOmish F, et al. Identification of genotypes of hepatitis $\mathrm{C}$ virus by sequence comparisons in the core, E1 and NS-5 regions. F Gen Virol 1994;75: 1053-61.

113 Okamoto H, Sugiyama Y, Okada S, et al. Typing hepatitis $\mathrm{C}$ virus by polymerase chain reaction with type-specific primers: application to clinical surveys and tracing infectious sources. $\mathcal{F}$ Gen Virol 1992;73:673-9.

114 McOmish F, Chan S-W, Dow BC, et al. Detection of three types of hepatitis $\mathrm{C}$ virus in blood donors: investigation of type-specific differences in serologic reactivity and rate of alanine aminotransferase abnormalities. Transfusion 1993; 33:7-13.

115 Stuyver L, Rossau R, Wyseur A, et al. Typing of hepatitis C virus isolates and characterization of new subtypes using a line probe assay. F Gen Virol 1993; 74:1093-102.

116 Dusheiko G, Schmilovitz-Weiss H, Brown D, et al. Hepatitis C virus genotypes: an investigation of type-specific differences in geographic origin and disease. Hepatology 1994;19:13-18

117 Booth J, Foster G, Kumar U, et al. Chronic hepatitis C virus infections: predictive value of genotype and level of viraemia on disease progression and response to interferon a. Gut 1995;36:427-32.

118 Kanai K, Kako M, Okamoto H. HCV genotypes in chronic hepatitis C and response to interferon. Lancet 1992;339: 1543.

119 Tsubota A, Chayama K, Ikeda K, et al. Factors predictive of response to interferon- $\alpha$ therapy in hepatitis $\mathrm{C}$ virus infection. Hepatology 1994;19:1088-94.

120 Gabrielli C, Zannini A, Corradini R, et al. Spread of hepatitis $\mathrm{C}$ virus among sexual partners of HCVAb positive intravenous drug users. F Infect 1994;29:17-22.

121 Rice P, Smith D, Simmonds P, et al. Heterosexual transmission of hepatitis C virus. Lancet 1993;342:1052-3.

$122 \mathrm{Kao} \mathrm{J}-\mathrm{H}$, Chen P-J, Yang P-M, et al. Intrafamilial transmission of hepatitis $\mathrm{C}$ virus: the important role of infections between spouses. F Infect Dis 1992;166:900-3.

123 Foster G, Goldin R, Main J, et al. Management of chronic hepatitis C: clinical audit of biopsy based management algorithm. BMF 1997;315:453-8.

124 Lee A. Hepatitis C and haemophilia. BMF 1995;310 1619-20.

125 Poynard T, Leroy V, Cohard M, et al. Meta-analysis of interferon randomised trials in the treatment of viral hepatitis C: effects of dose and duration. Hepatology 1996;24: 778-89.

126 Causse X, Godinot H, Chevallier M, et al. Comparison of 1 or $3 \mathrm{MU}$ of interferon alfa- $2 \mathrm{~b}$ and placebo in patients with chronic non-A, non-B hepatitis. Gastroenterology 1991;101:497-502.

127 Alberti A, Chemello L, Bonetti P, et al. Treatment with interferon(s) of community-aquired chronic hepatitis and interferon(s) of community-aquired chronic hepatitis.
cirrhosis type C. F Hepatol 1993;17(suppl 3):S122-6.

128 Iino S, Hino $\mathrm{K}$, Kuroki $\mathrm{T}$, et al. Treatment of chronic hepatitis C with high dose interferon alpha-2b. A multicenter study. Dig Dis Sci 1993;38:612-18.

129 Saracco G, Rosina F, Abate ML, et al. Long-term follow-up of patients with chronic hepatitis $\mathrm{C}$ treated with different doses of interferon- $\alpha_{2 b}$. Hepatology 1993;18:13005.

130 Poynard T, Bedossa P, Chevallier M, et al. A comparison of three interferon alpha- $2 \mathrm{~b}$ regimens for the long-term treatment of chronic non-A, non-B hepatitis. $N$ Engl $7 \mathrm{Med}$ 1995;332:1457-62.

131 Boyer N, Marcellin P, Duchatelle V, et al. Sustained response after alpha interferon therapy in patients with chronic hepatitis C. Hepatology 1995;22:291A
132 Rumi M, Del Ninno E, Parravicini M, et al. A prospective randomised trial comparing lymphoblastoid to recombinant interferon alfa $2 \mathrm{a}$ as therapy for chronic hepatitis $\mathrm{C}$. Hepatology 1996;24:1366-70.

133 Farrell G, Bacon B, Goldin R, et al. Comparative study. Lymphoblastoid interferon alpha-n 1 improves long term response to a 6 month course of treatment in chronic hepatitis C compared with recombinant interferon alpha- $2 b$. Results of an international randomized controlled trial. Hepatology 1998;27:1121-7.

134 Reichard O, Andersson J, Schvarcz R, et al. Ribavirin treatment for chronic hepatitis C. Lancet 1991;337:1058-61.

135 Di Bisceglie A, Shindo M, Fong T-L, et al. A pilot study of ribavirin therapy for chronic hepatitis C. Hepatology 1994; 16:649-54.

136 Di Bisceglie A, Conjeevaram H, Fried M, et al. Ribavirin as monotherapy for chronic hepatitis $\mathrm{C}$ : a randomised, double-blind, placebo-controlled trial. Ann Intern Med 1995;123:897-903.

137 Bodenheimer H, Lindsay K, Davis G, et al. Tolerance and efficacy of oral ribavirin treatment of chronic hepatitis C: a multicenter trial. Hepatology 1994;20:207A.

138 Dusheiko G, Main J, Thomas H, et al. Ribavirin treatment for patients with chronic hepatitis C: results of a placebo-controlled study. F Hepatol 1996;25:591-8.

139 Brillanti S, Garson J, Foli M, et al. A pilot study of combination therapy with ribavirin plus interferon alpha for interferon alpha-resistant chronic hepatitis C. Gastroenterology 1994;107:812-17.

140 Schalm S, Hansen B, Chemello L, et al. Ribavirin enhances the efficacy but not the adverse effects of interferon in chronic hepatitis C. Meta-analysis of individual patient data from European centres. $\mathcal{F}$ Hepatol 1997;26:961-6.

141 Braconier J, Paulsen O, Engman K, et al. Combined alphainterferon and ribavirin treatment for chronic hepatitis C interferon and ribavirin treatment for chronic

142 Chemello L, Cavaletto L, Bernardinello E, et al. The effect of interferon alpha and ribavirin combination therapy in naive patients with chronic hepatitis C. I Hepatol 1995;23(suppl 2):8-12

43 Reichard O, Norkrans G, Fryden A, et al. Randomised, double-blind, placebo-controlled trial of inteferon $\alpha-2 b$ with and without ribavirin for chronic hepatitis C. Lancet 1998;351:83-7.

144 Poynard T, Marcellin P, Lee S, et al. Randomised trial of interferon alpha2b plus ribavirin for 48 weeks or for 24 weeks versus interferon alpha2b plus placebo for 48 weeks for treatment of chronic infection with hepatitis $C$. International Hepatitis Interventional Therapy Group (IHIT). Lancet 1998;352:1426-32.

145 McHutchinson J, Gordon S, Schiff E, et al. Interferon alfa- $2 \mathrm{~b}$ alone or in combination with ribavirin as initial reatment for chronic hepatitis C. Hepatitis Interventional Therapy Group. N Engl ₹ Med 1998;339:1485-92.

146 Ishak K, Baptista A, Bianchi L, et al. Histological grading and staging of chronic hepatitis. F Hepatol 1995;22:696-9.

147 Marcellin P, Levy S, Benhamou J, et al. Management of the asymptomatic HCV carrier with normal ALT levels. Viral Hepat Rev 1996;2:277-83.

148 Serfaty L, Chazouillieres O, Pawlotsky J, et al. Interferon alpha therapy in patients with chronic hepatitis $\mathrm{C}$ and persistently normal aminotransferase activity. Gastroenterology 1996;110:291-5.

149 Jouet P, Roudot-Thoraval F, Dhumeaux D, et al. Comparative efficacy of interferon alpha in cirrhotic and non-cirrhotic patients with non-A non-B hepatitis. Gastroenterology 1994;106:686-90.

150 Idilman R, Maria N, Colantoni $\mathrm{A}$, et al. Interferon reatment of cirrhotic patients with chronic hepatitis C. 7 Viral Hepat 1997;4:81-91.

151 Mazzella G, Accogli E, Sottili S, et al. Alpha-interferon treatment may prevent hepatocellular carcinoma in HCVrelated liver cirrhosis. F Hepatol 1996;24:141-7.

152 Fattovich G, Giustina G, Degos F, et al. Effectiveness of interferon alpha on incidence of hepatocellular carcinoma and decompensation in European patients with cirrhosis type C. F Hepatol 1997;27:201-5.

153 Serfaty L, Giral P, Loria A, et al. Factors predictive of the esponse to interferon in patients with chronic hepatitis $C$. 7 Hepatol 1994;21:12-17.

154 Van Thiel D, Friedlander L, Fagiuoli S, et al. Response to interferon $\alpha$ therapy is influenced by the iron content of the liver. $\mathcal{F}$ Hepatol 1994;20:410-15.

155 Orito E, Mizokami M, Mizoguchi N, et al. Hepatitis C virus serotype II responds more favorably to interferon- $\alpha$ herapy. F Hepatol 1994;21:130-2.

156 Davis G, Lau J. Factors predictive of a beneficial response to therapy of hepatitis C. Hepatology 1997;26(suppl 1):122-7S.

157 Brouwer J, Nevens F, Kleter G, et al. Efficacy of interferon dose and factors predictive of sustained response in chronic hepatitis C: final results of a Benelux study in 350 patients. f Hepatol 1995;23:85.

158 Hagiwara H, Hayashi N, Mita E, et al. Quantitative analyis of hepatitis $\mathrm{C}$ virus RNA in serum during interferon alfa therapy. Gastroenterology 1993;104:877-83.

159 Lau JYN, Davis GL, Kniffen J, et al. Significance of serum hepatitits $\mathrm{C}$ virus RNA levels in chronic hepatitis C. Lancet 1993;341:1501-4.

160 Okada S-I, Akahane Y, Suzuki H, et al. The degree of variability in the amino terminal region of the E2/NS1 protein of hepatitis $C$ virus correlates with responsiveness to interof hepatitis C virus correlates with responsiveness to inter-
feron therapy in viremic patients. Hepatology 1992;16:61924 . 
161 Kanazawa Y, Hayashi N, Mita E, et al. Influence of viral quasispecies on effectiveness of interferon therapy in

62 Enomoto N, Sakuma I, Asahina Y, et al. Comparison of 2 Enomoto N, Sakuma I, Asahina Y, et al. Comparison of
full-length sequences of interferon-sensitive and resistant full-length sequences of interferon-sensitive and
hepatitis C virus 1b. $\mathcal{F}$ Clin Invest 1995;96:224-30.

163 Lindsay K, Davis G, Schiff E, et al. Response to higher doses of interferon alfa- $2 b$ in patients with chronic hepatitis C: a randomised multicenter trial. Hepatology 1996;24 1034-40.

164 McHutchinson J, Sedghi-Vaziri A, Russell J, et al. Is there an optimal time to measure quantitative HCV RNA to predict outcome following interferon treatment for chronic HCV infection? Hepatology 1996;24:356A.

165 Alberti A, Chemello L, Noventa F, et al. Therapy of hepatitis C: Re-treatment with alpha interferon. Hepatology 1997;26 (suppl 1):137-42S.

166 Sostegni R, Ghisetti V, Pittaluga F, et al. Sequential versus concomitant administration of ribavirin and interferon alpha-n 3 in patients with chronic hepatitis $\mathrm{C}$ not responding to interferon alone: results of a randomised, controlled ing to interferon alone: results of
trial. Hepatology 1998;28:341-6.

167 Moreno-Monteagudo J, Fernandez-Bermejo M, GarciaBuey L, et al. Interferon alpha with ribavirin for the treatment of chronic hepatitis C in non-responders or relapsers to interferon monotherapy. Aliment Pharmacol Ther 1998;12:717-23.

168 Bellobuomo A, Mondazzi L, Tempini S, et al. Ribavirin and interferon-alpha combination therapy vs interferonalpha alone in the treatment of chronic hepatitis C: a randomised clinical trial. $\mathcal{F}$ Viral Hepat 1998;4:185-91.
169 Davis G, Esteban-Mur R, Rustgi V, et al. Interferon alfa-2b alone or in combination with ribavirin for the treatment of relapse of chronic hepatitis C. International Hepatitis Interventional Therapy Group. N Engl f Med 1998;339:

170 Bennett W, Inoue Y, Beck J, et al. Estimates of the cost-effectiveness of a single course of interferon-alfa $2 \mathrm{~b}$ in patients with histologically mild chronic hepatitis C. Ann Intern Med 1997;127:855-65.

171 Dusheiko G, Roberts J. Treatment of chronic type B and C hepatitis with interferon alfa: an economic appraisal. Hepatology 1995;22:1863-73.

172 Pharoah P, Hollingworth W. Cost effectiveness of lowering cholesterol concentration with statins in patients with and without pre-existing coronary heart disease: life table method applied to health authority population. BMF 1996; 312:1443-8.

173 Buxton M, West R. Cost-benefit analysis of long term haemodialysis for chronic renal failure. BMF 1975;2:3769 .

174 Hart W, Rhodes G, McMurray J. The cost-effectiveness of enalapril in the treatment of chronic heart failure. $\mathrm{Br} \mathcal{F} \mathrm{Med}$ Economics 1993;6:91-8.

175 Wong J, McHutchinson J, Poynard T, et al, for the IHIT Group. Cost-effectiveness of initial ribavirin/interferon alfa-2b for chronic hepatitis C. Gastroenterology (in press). 176 Howie H. Scottish Health Purchasing Information Centre Executive Summary, 1999 (http://www.nhsconfed.net/ shpic.uk)

177 Weiland $\mathrm{O}$. Treatment of naive patients with chronic hepatitis C. F Hepatol 1999;31 (suppl 1):168-73. 